\title{
Raising the Accuracy of Shadow Economy Measurements*
}

\author{
VICENTE RÍOS IBÁÑEZ** \\ University of Milan \\ ANTONIO GÓMEZ GÓMEZ-PLANA*** \\ PEDRO PASCUAL ARZOZ**** \\ INARBE and Universidad Pública de Navarra
}

Received: March, 2021

Accepted: August, 2021

\begin{abstract}
This article estimates the size of the shadow economy in a Spanish region (Navarre) for the period 19862016. To this end, we employ indirect macro-econometric methods such as the Currency Demand approach, Electricity Consumption (Physical Input) methods and the multiple indicators multiple causes (MIMIC) approach. A differential feature of our empirical analysis is that we incorporate various methodological innovations (e.g. Bayesian Model Averaging, a Time-Varying Parameter model, normalization of the latent variable) to refine and increase the measurement accuracy of each of the indirect methods considered. The temporal pattern of the shadow economy's size that emerges from the different approaches is similar, which suggests that the estimates obtained are robust and capture the underlying dynamics of the hidden sector. After quantifying the shadow economy, we analyze its determinants by means of Bayesian Model Averaging techniques. We find that the evolution of the shadow economy in Navarre can be explained by a small and robust set of factors, specifically the tax burden, the share of employment in the construction sector, the inflation rate, euro area membership and the ratio of currency outside the banks to M1.
\end{abstract}

Keywords: Shadow economy, Currency demand, Electricity consumption, MIMIC, Bayesian model averaging.

JEL Classification: E26, H26, O17.

\footnotetext{
* The authors acknowledge financial support from: the Spanish Ministry of Economy and Competitiveness and the European Regional Development Fund (AEI/FEDER, EU), research projects ECO2016-76681-R and ECO201786054-C3-2-R; the Grant PID2020-114460GB-C32 funded by MCIN/AEI/10.13039/501100011033; the OTRI contract 2018903071 funded by Hacienda Foral Navarra. We would like to thank Alejandro Esteller, Fernando Rodrigo, Alberto Vaquero and the participants in the Symposium "Economía sumergida y fraude fiscal" (Pamplona, 2020) for their comments, and also to Luis Esáin, Maite Domínguez and Raquel Fuentes for their assistance and comments. The final version of this paper has benefited from the helpful comments of two anonymous referees and the editors. All remaining errors are ours.

** ORCID ID: 0000-0002-9678-1379.

*** ORCID ID: 0000-0003-3241-4358.

**** ORCID ID: 0000-0001-9561-6067.
} 


\section{Introduction}

The shadow economy can be defined as the realization of legal or illegal economic activities, which the law requires to be reported in full to the tax administration, but that are hidden to the authorities in order to avoid paying taxes or to circumvent certain regulations or administrative procedures (Organisation for Economic Co-operation and Development, OECD, 2017). ${ }^{1}$ Despite the relevance of the problem, not much is known about the magnitude of the shadow economy at subnational levels and its measurement and analysis remains a challenging task (Schneider and Buehn, 2017). In the empirical literature, there are two main approaches for estimating the size of the shadow economy: direct and indirect (Schneider and Enste, 2000).

Direct approaches refer to microeconomic methodologies that employ either well-designed surveys, samples based on voluntary replies, tax auditing or other compliance methods. Although these approaches can provide detailed information, they also present important drawbacks: they are expensive to carry out, respondents' willingness to cooperate is low and overall they are likely to underestimate the shadow economy, given that people are likely to under-declare what they are hiding from the authorities (Schneider and Buehn, 2017).

On the other hand, indirect approaches are mostly macroeconomic and use various economic indicators that contain information about the development of the shadow economy over time. The most widely used indirect approaches for investigating the shadow economy are: (i) the Currency Demand approach (Ahumada et al., 2007, 2008; Tanzi, 1983); (ii) Electricity Consumption (Physical Input) methods, comprising two variants, the Kaufmann and Kaliberda (1996) approach and the Lackó (1996, 1998, 2000) approach); and (iii) the Multiple Indicators Multiple Causes (MIMIC) method (Dell'Anno et al., 2007; Dell'Anno and Schneider, 2009; Giles, 1999a).

In this study, we measure the size of the shadow economy of the Spanish region of Navarre for the period 1986-2016 by employing all the above-mentioned indirect methods. These methods are based on different assumptions and each of them has its strengths and weaknesses. However, at present there is no obvious way to establish and evaluate which method is the most effective. For this reason, the employment of these approaches in combination is an important task to shed light on the evolution of this elusive variable. We proceed in this way with the conjecture that if a diverse pool of approaches generates similar measurements and patterns over time with respect to this unobserved variable, one may conclude that the estimates are relatively robust. By contrast, if the results and the temporal profiles of the shadow economy derived from these approaches are very diverse, one may conclude that the reliability of the estimates is limited and it is difficult to establish which one to trust.

Therefore, against the general trend in the literature analyzing the shadow economy by focusing on just one method, the main contribution of this study is to obtain new estimates of the size of the shadow economy by using three distinct approaches. A second key point of the empirical analysis performed here is that we introduce methodological innovations in each of these indirect approaches, enabling us to refine the measurements of the shadow economy and solve some of their weaknesses. Specifically, a Bayesian Model Averaging 
(BMA) estimation algorithm is applied to both the Currency Demand approach and Lackó's (1996, 1998, 2000) Electricity Consumption analysis. In addition, a Time-Varying Parameter model is estimated in the context of the analytical framework developed by Kaufmann and Kaliberda (1996). Finally, within the context of the MIMIC approach, a novel identification and normalization of the estimated latent variable is proposed.

As mentioned before, our testing ground is the Spanish region of Navarre. This region is especially compelling for the following reasons.

First, Navarre historically has had broad fiscal autonomy, both in its regulatory capacity and in the management of tax collection. Furthermore, according to Sorens (2014), it is in the top $1 \%$ of the regional distribution of economic self-rule in Europe. Navarre's special status (régimen foral) implies a bilateral relationship with the national government. The financial and tax activity of Navarre is ruled by the Economic Agreement (Convenio Económico) with the national government, and regulated in Law 28/1990. The Basque Country has a similar status in Spain. The Economic Agreement follows a very different logic from that of the financing system of the normal status regions. It establishes the criteria for tax harmonization and determines the method for calculating the region's economic contribution (Aportación Económica) for the national expenditure policies not assumed by Navarre (e.g. military defence, international diplomacy) and for adjustments in tax collection. ${ }^{2}$ Hence, Regional Treasury of Navarre collects and inspects practically all taxes (excluding social contributions) and then transfers part of its revenue to the national government.

Second, with regard to the regional implementation of policies to confront fiscal fraud, there is cooperation with the National Tax Agency and the provincial tax agencies of the Basque Country. Navarre designs and implements its own tax control plan, establishing as strategic objectives both prevention and voluntary compliance as well as fighting against fiscal fraud. Another important objective is to avoid strategic behaviours that seek to take advantage of regulatory differences across territories, for example through relocation or abusive tax planning.

Third, there is some evidence that Spain's special status regions obtain better economic outcomes in the public expenditure directly linked to their fiscal regime (Zubiri, 2015) and that the quality of their institutions is higher than the national average (Charron et al., 2014). For example, these regions provide better public services with a lower fiscal burden. Zubiri (2015) has estimated several public services indexes to measure their quality and per capita expenditure in education, health services, social services and infrastructure, finding Navarre and the Basque Country to be well above the Spanish average in all indicators. Pérez García et al. (2011) have also found that the total public expenditure per capita of the special status regions clearly exceeds than in the rest of Spain. On the public revenue side, Esteller (2021) has found that Navarre's real income tax rates are very close to optimal, manifesting the smallest gap among all Spanish regions. Nevertheless, the Basque Country has a much wider gap between real and optimal income tax rates.

Fourth, the economic structure of Navarre is quite different from that of Spain because of the region's manufacturing bias. For example, in terms of value added and employment 
in manufacturing, Navarre's size has remained around twice that of the rest of Spain during the past two decades. Moreover, according to the Economic Complexity Index ${ }^{3}$ proposed by Haussman et al. (2014) and calculated by BBVA (2017), Navarre has the most complex economic structure of all Spanish regions.

Fifth, differences exist between the special status regions and the national framework on tax collection. Navarre and the Basque Country have shared a relatively common pattern during the past three decades, which differs from the national pattern. At the national level, the share of direct taxes on total taxes has remained larger than the share of indirect taxes. For the two special status regions, the leading share has been changing but both show the same time pattern. Another difference is linked to direct taxation, where there is a much more relevant share of corporate taxes in Spain than in Navarre (e.g. 32.7\% in Spain and 14.5\% in Navarre in 2015). Nevertheless, the similarities are large with respect to indirect taxation, where the value added tax (VAT) has represented around $70 \%$ of the revenue and excise duties around $20 \%$ during the past two decades for both Spain and Navarre.

Taken together, these structural differences suggest that the size of the underground economy in Navarre and even its determinants may differ from what has been previously analyzed at the Spanish level; see Fernández-Leiceaga et al. (2018) for a recent review.

This article is organized as follows. Section 2 presents the Currency Demand approach. Section 3 describes the main features of the two Electricity Consumption approaches and presents the results obtained. Section 4 explains the MIMIC method and the estimation results. Finally, Section 5 offers the main conclusions and summarizes the findings of this research.

\section{The Currency Demand Approach}

The Currency Demand approach (CDA) is one of the most widely used approaches for estimating the shadow economy (Ahumada et al., 2007, 2008; Cagan, 1958; Gutmann, 1977; Tanzi, 1983). Several studies have previously employed this method for Spain at the national (Arrazola et al., 2011; Gadea and Serrano-Sanz, 2002; Prado-Domínguez, 2004) and regional levels (González-Fernández and González-Velasco, 2015).

The CDA analyzes the behaviour of currency or cash in circulation and links it to the tax burden. The rationale behind the CDA is that if tax rates increase, Currency Demand will also increase, as cash is a useful vehicle for concealing potentially taxable income (Schneider, 2005). The CDA assumes that opaque transactions are carried out in the form of cash payments to reduce their traceability by the tax authorities. The intuition behind this assumption is that while transactions made with cash are difficult to track, those made with other forms of money recorded in financial institutions can be more easily inspected. Therefore, an increase in the shadow economy will tend to increase currency or cash demand. A second core assumption is that if there were no taxes, the incentives to carry out opaque transactions would also disappear. Therefore, ceteris paribus, high tax levels should translate into a larger size of the shadow economy. 
One key advantage of the CDA is that it does not need an exogenous initial condition to generate predictions, as is the case with other methods. There is a broad consensus that this approach is the most reliable and safe procedure for data collection, econometric processing and temporal consistency if the appropriate monetary aggregate is chosen. However, among its drawbacks it is worth noting that: (i) not all transactions in the underground economy are paid in currency; (ii) the empirical evidence points not only to taxes as responsible for variations in the shadow economy but also to other causes like fiscal morality and regulations; (iii) payments in cash are becoming less and less frequent, not only because of the use of electronic means but also due to the restrictions established for the prevention of money laundering, based on a maximum amount of cash payments; and (iv) there are difficulties in estimating the amount of money and its speed at the regional level, which can lead to measurement errors.

In this regard, the lack of reliable regional data and sufficiently long time series is particularly problematic. As a consequence, researchers have often restricted the number of regressors in their econometric specifications in order to avoid multicollinearity problems and obtain efficient parametric estimates (see González-Fernández y González-Velasco, 2015; Pickhardt and Sardá, 2015). However, efficiency gains have come at the cost of a potential bias in the parameter estimates due to potentially relevant factors being omitted and the role of model uncertainty being neglected.

We attempt to solve these problems by (i) building a longer regional time series of regional currency consistent with the economic and demographic evolution of Navarre; and (ii) using a BMA approach to address the model uncertainty problems affecting the reliability of money demand equation specifications and the accuracy of the estimates in the literature. The main advantage of the CDA-BMA employed here is that it accounts for the uncertainty of parameter estimates within and across all potential models in the CDA given a set of candidate determinants. At the same time, it allows one to control for omitted variable bias and reduces collinearity issues, which is relevant in order to obtain credible estimates of the impact of taxes on currency.

\subsection{Data and Methodology}

The Bank of Spain only provides information on monetary variables at the national level. Hence, to carry out our empirical analysis for Navarre, banknote and coin data must be regionalized. González-Fernández and González-Velasco (2015) suggest the use of the relative weight of the population of each region. However, the cash in circulation in a region depends not only on its population but also on its income level. Therefore, to obtain a more refined estimate, we consider both demographic and economic criteria. Regionalized cash $\left(C_{t}\right)$ is estimated from the national-level data $\left(C_{t}^{S P A}\right)$ for each period $t$, by applying a time-varying weight $w_{t}$, calculated as the arithmetic mean of the population's regional share $\left(w_{t}^{P O P}\right)$, the nominal GDP share $\left(w_{t}^{G D P N}\right)$ and the real GDP share $\left(w_{t}^{G D P R}\right)$ with respect to the country's total. That is:

$$
C_{t}=w_{t} C_{t}^{S P A}
$$


where

$$
w_{t}=(1 / 3) w_{t}^{P O P}+(1 / 3) w_{t}^{G D P N}+(1 / 3) w_{t}^{G D P R}
$$

The Currency Demand model for estimating the shadow economy in Navarre is drawn from Tanzi's (1983) work and has the following form:

$$
C_{t}=\alpha+\beta_{1} T_{t}+\beta_{2} \ln Y_{t}+\beta_{3} R_{t}+\beta_{4} \pi_{t}+\beta_{5} U_{t}+\sum_{k=1}^{K} \gamma_{k} Z_{t, k}+\varepsilon_{t}
$$

where the dependent variable $C_{t}=\ln \frac{M_{0 t}}{P_{t}}$ is the monetary aggregate in real terms (i.e. the logarithm of the real currency in circulation). The covariates are: the overall tax burden or fiscal pressure (including social contributions) $\left(T_{t}\right)$; the logarithm of regional real GDP $\left(\ln Y_{t}\right)$ linked to the scale of the demand; the interest rate $\left(R_{t}\right)$ and inflation $\left(\pi_{t}\right)$ reflecting the opportunity costs of holding cash; and the unemployment rate $\left(U_{t}\right)$.

Nevertheless, beyond this core set of regressors, there are numerous factors that may correlate with the tax burden, the GDP and the real currency and whose omission could bias the key estimates within this procedure (i.e. $\widehat{\beta_{1}}$ and $\widehat{\beta_{2}}$ ). Thus, we also include a matrix $\boldsymbol{Z}$ of potential determinants that could affect the demand for currency. These are (i) socio-demographic factors (education and net migration). Education levels matter for the adoption and use of new payment instruments; moreover, with increased education, the use of electronic money becomes more likely, which in turn reduces the use of cash (Koulayev et al., 2016). Education may also have a positive effect on demand for cash, given that the higher the education, the higher the labour income and so the higher the absolute demand for currency. Positive net migration levels triggered by wage differences between the region of origin and the destination may increase the demand for currency, especially if the inflow of population consists of illegal migrants (Camacho et al., 2017). This is because illegal migrants can only work in the informal sector and firms operating in the shadow economy which hire illegal immigrant labour usually employ cash to pay wages and avoid taxes (Horodnic, 2016). Other effects can be related to legal and illegal migrants: although it may be expected that the larger (smaller) the population, the larger (smaller) the absolute demand for currency, net migration can bias the pattern of the aggregate population's demand for cash due to changes in savings behaviour, human capital level, remittances and other factors.

Another set of variables in $\boldsymbol{Z}$ are related to (ii) labour market and productive structure factors (percentage of employment in agriculture, industry, construction, non-market services, financial services, market services, etc.). The sectoral composition may be relevant in this context, given that the demand for currency depends on the size and the number of transactions and the degree of uncertainty faced by economic agents, which all vary across productive sectors (Choi et al., 2018; Rua, 2018). In addition, there is evidence that pockets of informal employment largely vary across sectors, affecting the incentives to hold cash (Hassan and Schneider, 2016a, 2016b; Schneider, 2013). Finally, there is evidence that in the long run, labour shares matter for the distribution of income (Bengtsson and Waldenström, 2018) and, according to transaction theories, money demand should decline as aggregate income becomes more unequally distributed (Cover and Hooks, 1993). 
Finally, we follow González-Fernández and González-Velasco (2015) by controlling for various (iii) monetary events (e.g. entry into the euro area in 2002; the Great Recession of 2008-2013, which increased the marginal propensity to save in many countries) and including (iv) a linear and a quadratic trend.

In total, we consider eighteen variables for this augmented money demand specification, five of which are fixed and common to all specifications and thirteen of which may enter (or not) a specific model combination. Note that in this context, there are many sub-models $M_{k}$, for $k=1, \ldots, 2^{K}$; of the model in Equation (3) given by the subsets of coefficients $\eta^{k}=\left(\alpha^{(k)}, \beta^{(k)}, \gamma^{(k)}\right)$ and the combinations of regressors, where $K=13$ is the number of regressors in $\boldsymbol{Z}$. A number of questions arise when there are so many potential explanatory variables. Which set of variables should be included in the model? How important are they? BMA techniques solve these questions by estimating all the candidate models implied by the combinations of regressors (or a relevant sample of them) and computing a weighted average of all the estimates. By proceeding in this way, the estimates consider both the uncertainty associated with the parameter estimate conditional on a given model and the uncertainty of the parameter estimate across different models.

By following the Bayesian logic, the posterior distribution of the parameters $\eta_{k}$ calculated using model $M_{k}$ is written as:

$$
g\left(\eta_{k} \mid D, M_{k}\right)=\frac{f\left(D \mid \eta_{k}, M_{k}\right) g\left(\eta_{k} \mid M_{k}\right)}{f\left(D \mid M_{k}\right)}
$$

where $g\left(\eta_{k} \mid D, M_{k}\right)$ is the posterior, $f\left(D \mid \eta_{k}, M_{k}\right)$ is the likelihood, $g\left(\eta_{k} \mid M_{k}\right)$ is the prior and $D=(y, X, Z)$ is the sample data. The key metrics in BMA analysis are the weighted posterior mean (PM) of the distribution of $\eta$ :

$$
E(\eta \mid y, X)=\sum_{k=1}^{2^{K}} E\left(\eta_{k} \mid M_{k}, D\right) p\left(M_{k} \mid D\right)
$$

and the posterior standard deviation (PSD):

$$
P S D=\sqrt{\operatorname{Var}(\eta \mid D)}
$$

To derive these metrics, it is necessary to calculate the posterior model probability $p\left(M_{k} \mid D\right)$ of each of the sub-models $M_{k}$. These can be obtained as:

$$
p\left(M_{k} \mid D\right)=\frac{p\left(D \mid M_{k}\right) p\left(M_{k}\right)}{\sum_{k=1}^{2^{K}} p\left(D \mid M_{k}\right) p\left(M_{k}\right)}
$$

where $p\left(D \mid M_{k}\right)$ is the marginal likelihood and $p\left(M_{k}\right)$ is the prior model probability. The marginal likelihood of a model $k$ is calculated as:

$$
p\left(D \mid M_{k}\right)=\int_{0}^{\infty} \int_{-\infty}^{\infty} p\left(D \mid \eta_{k}, \sigma^{2}, M_{k}\right) p\left(\eta_{k}, \sigma^{2} \mid g\right) d \eta d \sigma
$$


where $p\left(D \mid \eta, \sigma, M_{k}\right)$ is the likelihood of model $k$ and $p\left(\eta_{k}, \sigma^{2} \mid g\right)$ is the prior distribution of the parameters in model $M_{k}$ conditional on $g$, Zellgner's g-prior. ${ }^{4}$ In addition, the BMA framework can be used to generate a probabilistic ranking of the relevance of the various regressors, by using the posterior inclusion probability (PIP) for a variable $h$ :

$$
p\left(\eta_{h} \neq 0 \mid D\right)=\sum_{k=1}^{2^{K}} p\left(M_{k} \mid \eta_{h} \neq 0, D\right)
$$

An additional relevant metric is the conditional posterior positivity of $h$ :

$$
p\left(\eta_{h} \geq 0 \mid D\right)=\sum_{k=1}^{2^{K}} p\left(\eta_{k, h} \mid M_{k}, D\right) p\left(M_{k} \mid D X\right)
$$

where values of conditional positivity close to 1 indicate that the parameter is positive in the vast majority of considered models and values close to 0 indicate that the effect on the dependent variable is negative. As it is common in BMA analysis, we use a Monte Carlo Markov chain model composition $\left(\mathrm{MC}^{3}\right)$ sampler with birth, death and move steps to explore the relevant parts of the model space (see Zeugner and Feldkircher, 2015).

Thus, the CDA-BMA implemented here estimates the ratio of the shadow GDP $\left(Y S_{t}\right)$ to the official $\operatorname{GDP}\left(Y_{O, t}\right)$ through a sequential procedure:

1. Estimate the Currency Demand model (Equation 3) using the BMA approach to obtain $\widehat{C}_{t}=\ln \frac{\widehat{M}_{t}}{\widehat{P}_{t}}$.

2. Perform a counterfactual by 'shutting down' the effect of taxes to obtain $\left[\widehat{C_{t}^{c}}\left(\widehat{\beta_{1}}=0\right)\right]$, which is equivalent to measuring the hypothetical trajectory of $C_{t}$ if the taxes were at the $0 \%$ mark or if the tax burden $T_{t}$ had remained constant.

3. Calculate the demand for cash attributable to the shadow activities arising from the existence of taxes and/or their time variations as the difference between time series: $\widehat{c_{t}}=\exp \widehat{C_{t}}-\exp \widehat{C_{t}^{c}}\left(\widehat{\beta_{1}}=0\right)$.

4. With $\widehat{c_{t}}$ in hand, use Fisher's quantitative equation $M_{t} \times V_{t}=P_{t} \times T_{t}$ to determine the size of the shadow economy. Specifically, obtain the velocity of money $\widehat{V}_{t}=\frac{P_{t} x T_{t}}{M_{t}}$ where $M_{t}$ is the money supply (i.e. the stock of liquid assets available in the economy) and $P_{t} x T_{t}$ is the total value of transactions for goods and services ${ }^{5}$. Then, use $\widehat{V}_{t}$ to transform the Currency Demand data into a series of hidden GDP $^{6}$ using the fact that $\widehat{Y S_{t}}=\widehat{c_{t}} \times \widehat{V_{t}}$.

5. Finally, following Ahumada et al. (2008), compute the ratio of the shadow economy adjusted for the elasticity of real GDP as $S E_{t}=\left(\frac{\widehat{Y S_{t}}}{Y_{O, t}}\right)^{\frac{1}{\overline{\beta_{2}}}}$ if $\widehat{\beta_{2}} \neq 1$. Note that 
because in this CDA-BMA we are working with many different estimates for each period coming from many different models, each model-specific $\left(M_{k}\right)$ ratio of the shadow economy $\widehat{S E}_{t, k}$ is averaged using Equation (11) to produce our final estimate:

$$
\widehat{S E}_{t}=\sum_{k=1}^{2^{K}}\left(\widehat{S E}_{t, k} \mid M_{k}, D_{t}\right) p\left(M_{k} \mid D_{t}\right)
$$

\subsection{Results}

A feature of our CDA-BMA is that we further restrict the set of accepted candidate models by checking for each model $M_{k}$ if (i) $7.5 \%<S E_{t} \mid M_{k}<50 \%$ and (ii) $\widehat{\beta_{1}} \mid M_{k}>0$. This ensures that we filter out absurd models with unrealistic and exorbitant initial estimates for the year 1986 and excessively low values for 2016; and that we eliminate model draws with parameters that violate the basic theory of the CDA.

The results of the BMA regression analysis are reported in Table A2 in the Appendix for the interested reader. Here we simply note the two main points. First, the model-averaged effect of the overall tax burden is 2.76 and the variable appears significant at the $5 \%$ level in $54.7 \%$ of the regressions. Hence, a $1 \%$ increase in the aggregate tax burden generates an increase in the demand for currency of $2.8 \%$. Second, a $1 \%$ change in the real GDP increases by $2.54 \%$ the demand for currency, implying an elasticity greater than unity that is within the range of values previously reported in the literature for Spain. ${ }^{7}$

Figure 1

\section{CURRENCY DEMAND MODELS: A GRAPHICAL OVERVIEW}

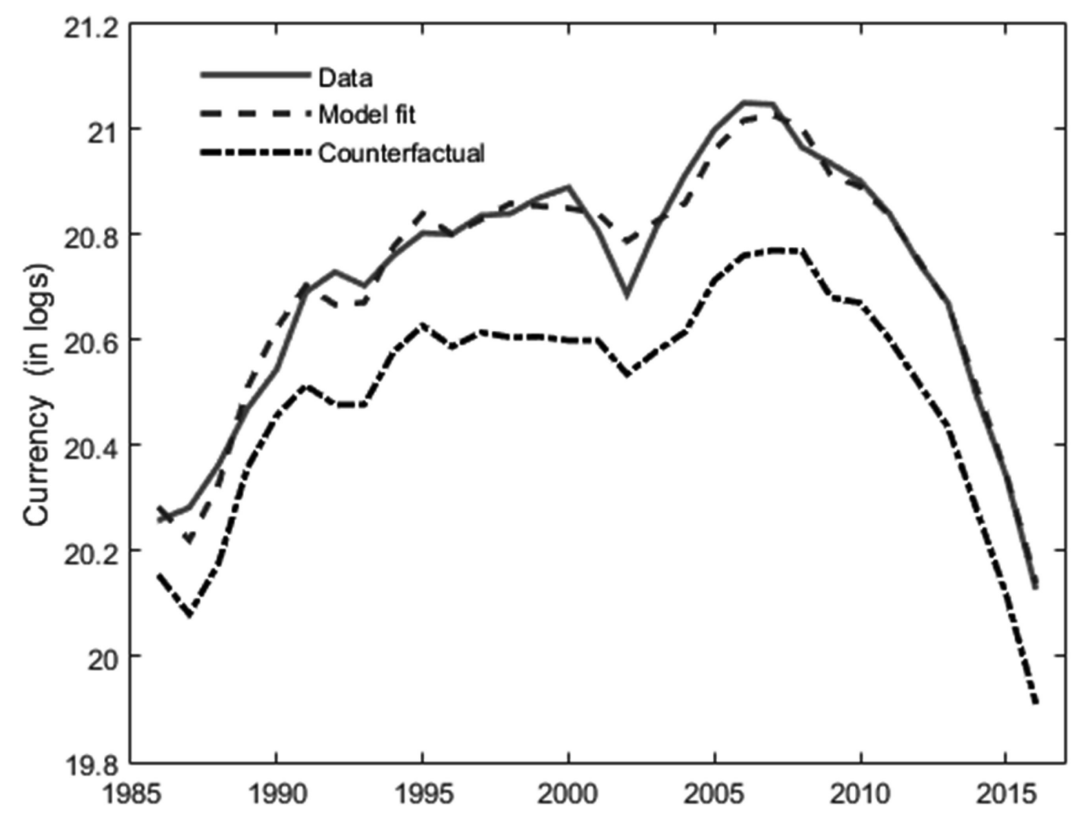


In a second step, we use these model-averaged parameters to estimate $\widehat{C_{t}}$. The red dashed line in Figure 1 represents the BMA fit to the data, while the blue line represents the actual historical trajectory. As can be seen, the BMA fit replicates with precision the evolution of currency in Navarre, the only exception being the year in which the euro was adopted. On the other hand, the dash-dotted black line is the counterfactual of the hypothetical evolution of the logarithm of currency $\widehat{C_{t}^{c}}\left(\widehat{\beta_{1}}=0\right)$ for a case in which either the taxes are $0 \%$ or the tax burden remains constant. The difference between the fit of the model and the counterfactual simulation, $\widehat{c_{t}}=\exp \widehat{C_{t}}-\exp \widehat{C_{t}^{c}}\left(\widehat{\beta_{1}}=0\right)$, provides the amount of cash demanded to carry out shadow transactions. ${ }^{8}$

Figure 2

\section{CURRENCY DEMAND MODELS: SHADOW ECONOMY SIZE (as \% of GDP) WITH TOTAL TAX BURDEN (including Social Contributions)}

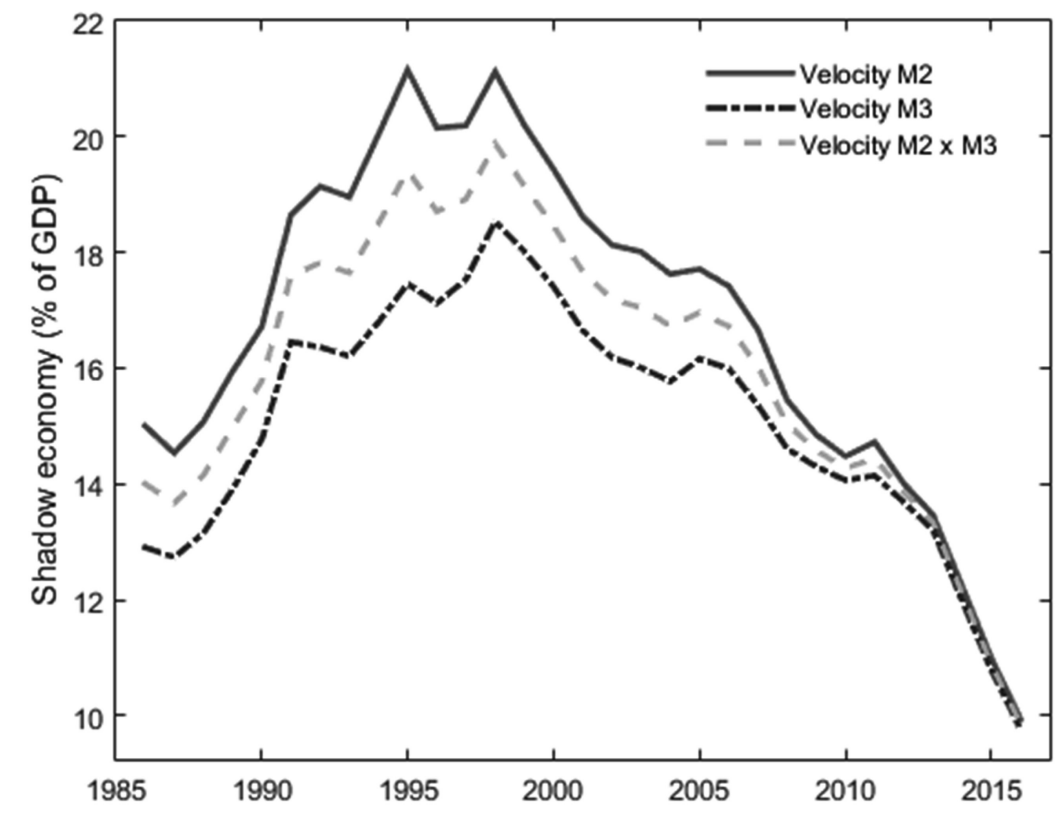

Fisher's equation is then used to convert $\widehat{C_{t}}$ into an informative indicator of the magnitude of shadow economic activity. This estimate is multiplied by the velocity of money $\widehat{V}_{t}$. An essential task in this regard is to select the proper monetary aggregate to derive $\widehat{V}_{t}$. Gadea and Serrano-Sanz (2002) and González-Fernández and González-Velasco (2015) show that the use of smaller (larger) monetary aggregates suggests a higher (lower) velocity in the underground economy than in the official economy. Furthermore, the use of M1 may lead to an overestimation of the size of the informal sector, as its velocity has increased in recent years due to financial innovation. For this reason, the velocity of the monetary aggregates M2 and M3 as well as the average velocity between them are used to generate different scenarios. The results are shown in Figure 2. As can be observed, different money velocities imply different 
sizes of the shadow economy. Whereas the use of the velocity of M2 gives a historical average of $17.25 \%$, the use of the velocity of M3 gives a value of $15.43 \%$. On the other hand, the average of these two money velocities implies an average shadow economy size of $16.38 \%$, which is our preferred baseline CDA measurement. Importantly, this average value closely resembles that of González-Fernández and González-Velasco (2015), who have estimated the size of the shadow economy in Navarre to be between $17.3 \%$ and $19.2 \%$ for the period 1987-2010 depending on the fiscal indicator employed.

Note that the figures presented so far assume that the overall tax burden (including social contributions) is the proper tax indicator to include in the CDA-BMA regressions. Nevertheless, there is also uncertainty with respect to the relevant tax indicator, as different tax variables may produce diverse estimates of the size of the shadow economy. In fact, for different fiscal indicators of the tax burden (as a percentage of the GDP), a researcher can obtain an average size of the shadow economy and a time profile that differs from that of the overall tax burden (see Table A2 in the Appendix). For the case of Navarre, the estimates of the size of the shadow economy based on aggregate direct taxes $(21.56 \%)$, corporate tax $(17.04 \%)$ and income tax $(28.78 \%)$ are higher than those of our baseline measurement of $16.3 \%$. By contrast, the estimates obtained with the total indirect taxes (15.19\%), the VAT $(15.24 \%)$ and the total tax burden (excluding social contributions) (15.59\%) are lower. This suggests that using information regarding a single tax indicator may underestimate or overestimate the true size of the shadow economy.

\section{Figure 3}

CURRENCY DEMAND MODELS: SHADOW ECONOMY SIZE (as \% of GDP) WITH TOTAL TAX BURDEN (including Social Contributions) VS BMA

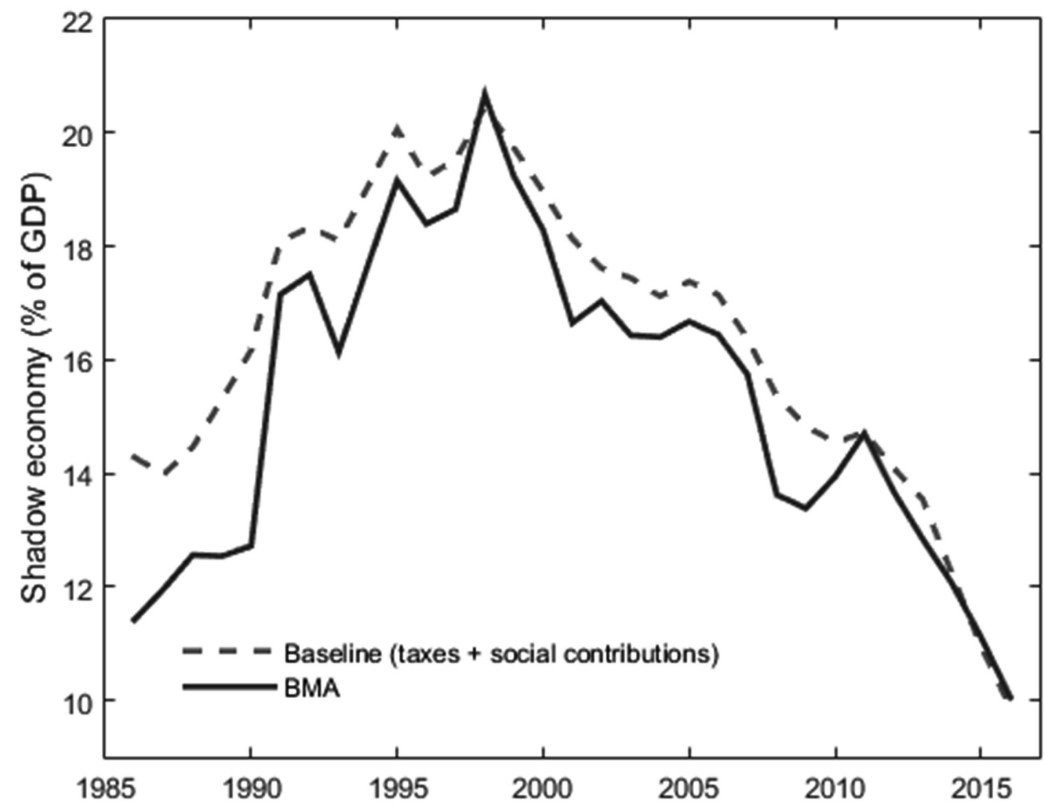


The issue of what fiscal indicator researchers should use for CDA analysis has been discussed in detail in the literature (Gadea and Serrano-Sanz, 2002; González-Fernández and González-Velasco, 2015) and no consensus exists on how the estimates arising from a specific tax indicator should be selected. Fortunately, this conundrum can be solved within the framework of the BMA algorithm employed here by calculating the marginal likelihoods of all the models for each fiscal indicator $T_{j}$, integrating them to derive a new set of model probabilities $p\left(M_{j k}\right)^{\prime}$ and weighing each of the shadow economy estimates by their corresponding probability. Therefore, if the probability of the time pattern of the shadow economy ratio implied by a specific tax indicator given the data is low, this procedure will attach a low weight to the shadow economy figures of this tax indicator when compared to those implied by other tax indicators. ${ }^{9}$

The results of the CDA-BMA using the updated model weights from all the sampled models and for each fiscal indicator are shown in Figure 3 in comparison with the baseline estimate. As can be observed, this procedure yields a historical average for the size of the hidden sector of $15.31 \%$ of the GDP (see the red solid line), one percentage point below the result obtained when applying the CDA-BMA with the aggregate tax burden indicator. ${ }^{10}$

Figure 4

\section{CDA-BMA SHADOW ECONOMY ESTIMATES FOR NAVARRE, SPAIN AND THE BASQUE COUNTRY}

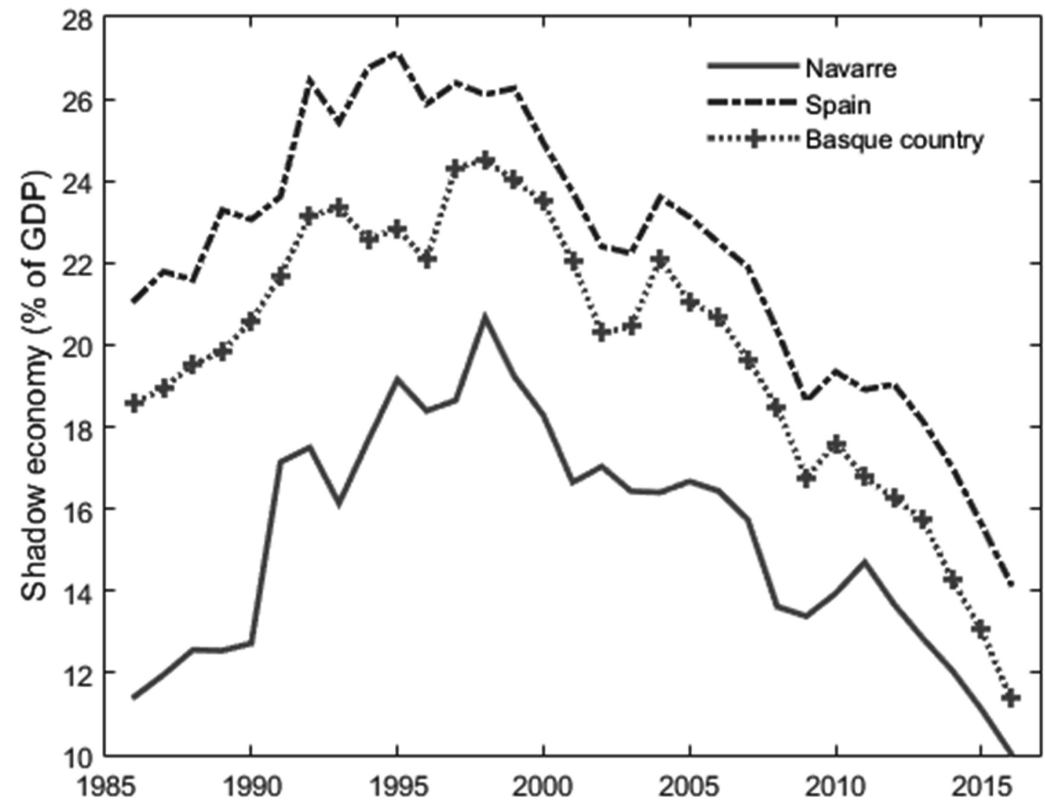

To contextualize the previous estimates of Navarre, we now repeat the whole process described before using data for the Basque Country region and Spain. ${ }^{11}$ Figure 4 jointly depicts the time trajectory obtained for the two regions and the national average. The graph 
shows that historically the economy of Navarre, with an average hidden sector size of $15.3 \%$, has been 6.9 points below the Spanish average (22.3\%). In addition, we can see that the average size of the hidden sector in Navarre has been smaller than that of the Basque Country (19.8\%). Nevertheless, in the year 2016 the size of the underground economy in Navarre $(10.05 \%)$ was quite close to that of the Basque Country $(11.3 \%)$, whereas the estimate for Spain $(14.2 \%)$ remained above the special status regions. These results are consistent with previous findings at the regional level by González-Fernández and González-Velasco (2015) and Zubiri et al. (2016), these authors also noting that the sizes of the shadow economy in Navarre and the Basque Country have been below the national average (see Figure 5).

\section{Figure 5 \\ REGIONAL DISTRIBUTION OF SHADOW ECONOMY ESTIMATES IN SPAIN}

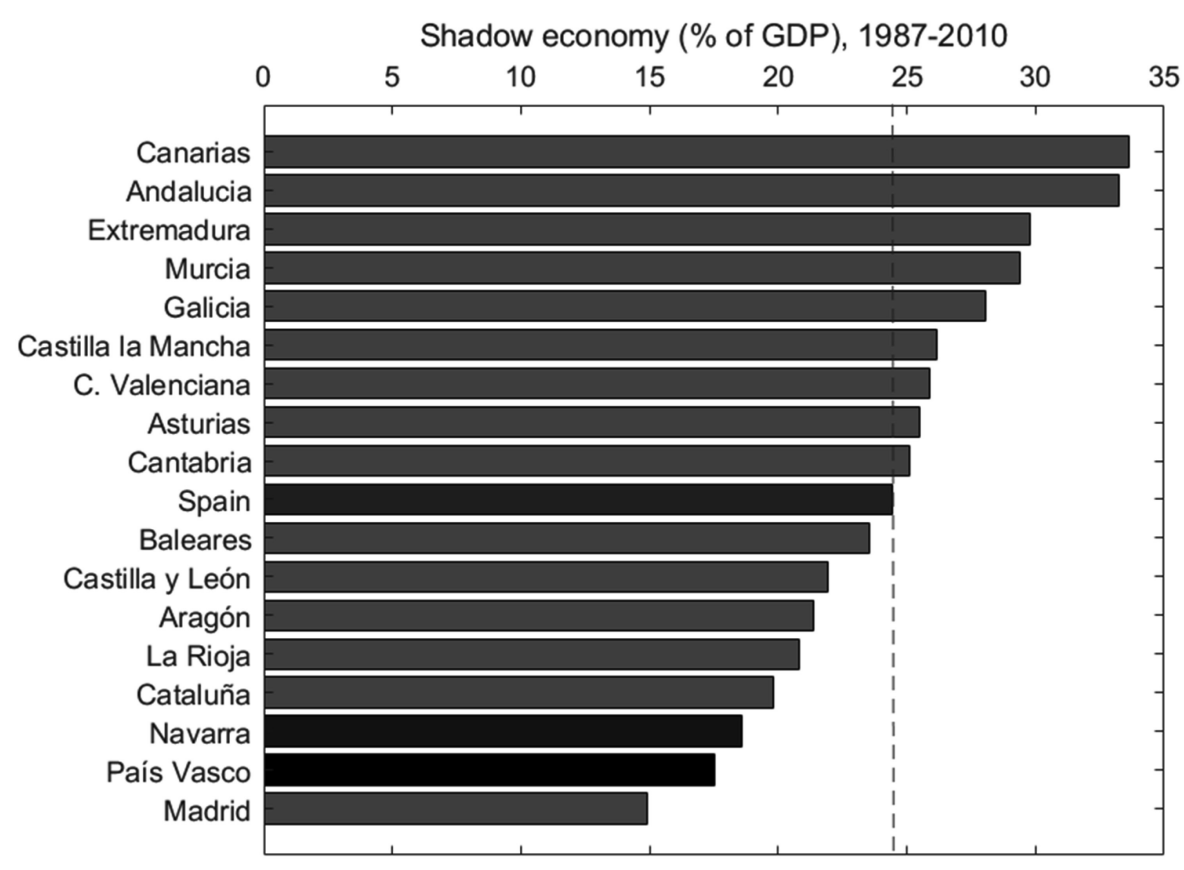

Source: Own elaboration based on data from González-Fernández and González-Velasco (2015).

It is also worth mentioning that our Spanish estimates based on the CDA-BMA are in line with the diverse measurements in the literature. Figure 6 reports the results implied by the CDA-BMA (red dashed line) and the median estimate of the size of the shadow economy obtained in Spain in the existing CDA literature (blue dotted line). To compute the average of the literature estimates, we use the measurements recorded in the literature review performed by Fernández-Leiceaga et al. (2018) covering the same period. Uncertainty regarding our measurement is simulated by drawing from a normal distribution $S E_{t} \sim N\left(\mu_{S E, t}, \sigma_{E, t}\right)$, where $\mu_{S E, t}$ is the mean size of the shadow economy at time $t$ and the standard deviation at each 
period $\sigma_{E, t}$ reflects the uncertainty of the estimates across models and within models. Interestingly, we find that the mean estimate in the literature falls within the upper $95 \%$ and lower $5 \%$ confidence bands for most of the period under consideration. In fact, the average size of the shadow economy for the study period implied by the mean of the CDA-BMA is $22.3 \%$, whereas the average in the literature implies a size of $20.6 \%$ of the GDP. The similarity in the estimated pattern is remarkable in the first twenty-five years, as they both display an increase in the size of the shadow economy up to a peak around the mid-1990s, followed by a decline.

Figure 6

COMPARISON OF SPAIN'S ESTIMATES WITH THE REVIEW OF THE CDA LITERATURE

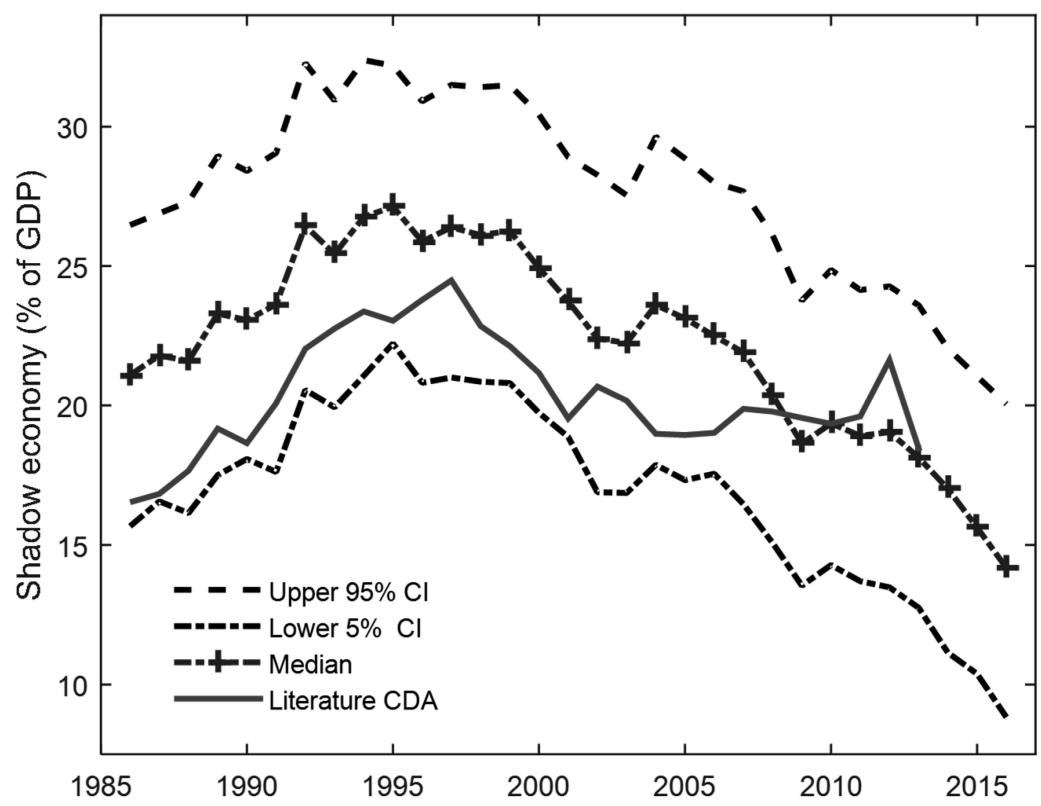

Source: Own elaboration based on data from Fernández-Leiceaga et al. (2018).

\section{Electricity Consumption Methods}

We now turn our attention to Electricity Consumption approaches. Developed by Kaufmann and Kaliberda (1996) (KK1996 henceforth) and Lackó (1996, 1998, 2000), these are based on the idea that the total consumption of electricity is a reliable indicator of the global activity of the economy and that discrepancies between electricity consumption and registered economic activity can aid in identifying the size of the shadow economy. Nevertheless, few studies have been carried out using these approaches, because not all underground activities require significant electricity consumption, a relevant flaw. We now describe these approaches and the innovations introduced to increase their accuracy in estimating the size of the shadow economy in Navarre. 


\subsection{The Kaufmann-Kaliberda Approach}

KK1996 assume that electricity consumption is the best indicator of overall economic activity and that the elasticity of electricity consumption with respect to GDP is generally very close to one (OECD, 2002). In KK1996, electricity consumption provides a proxy measure of 'overall economic activity', while GDP provides a measure of 'official economic activity'. Thus, the difference in the time path of these two variables allows the researcher to estimate the size of shadow economic activity. In addition to KK1996, scholars like Johnson et al. (1997) and Novkovska and Novivksi (2018) have used this approach.

According to Schneider and Buehn (2017), some of the advantages of the KK1996 method are: (i) it requires few variables and these are all easily available; (ii) it does not require the estimation of a large number of parameters; and (iii) given that the main variable used is a physical quantity which is well-defined and is determined with high accuracy, it may reduce measurement errors. However, Schneider and Buehn (2017) also argue that the KK1996 approach tends to generate very high or very low estimated values of the shadow sector. The main criticisms of KK1996 are that (i) not all activities in the shadow economy require a considerable amount of electricity (for example, personal and care services) and (ii) other energy sources (e.g. gas, oil, coal) can be used in the production process. Thus, this approach will only be indicative of a share of the underground economy. In addition, (iii) in recent decades, electricity production technology has advanced considerably, such that both the production and the use of electricity are currently more efficient than in the past. Therefore, considerable changes in the elasticity of GDP with respect to electricity consumption may have occurred during the sample period, affecting the quality of the estimates if these variations are not taken into account. To address this potential drawback, we extend the classical KK1996 approach and attempt to estimate this key elasticity with higher accuracy by relying on Time-Varying Parameter (TVP) regression models.

\subsubsection{Data and Methodology}

We follow Novkovska and Novivksi (2018) for the derivation of an analytical expression of the size of the shadow economy in this context. The total GDP in period $t\left(Y_{T, t}\right)$ is the sum of GDP in the official sector $\left(Y_{O, t}\right)$ and the shadow sector $\left(Y_{S, t}\right)$. It is assumed that the total GDP is proportional to the total electricity consumed $\left(E C_{t}\right)$ during period $t$, where $k$ is a constant of proportionality and $\phi=\frac{1}{\mu}$ is the elasticity of GDP with respect to electricity consumption. Thus, the relationship can be expressed as:

$$
Y_{T, t}=Y_{O, t}+Y_{S, t}=k \times E C_{t}^{\frac{1}{\mu}}
$$

The previous expression for the initial year $(t=0 \rightarrow 1986)$ is:

$$
Y_{O, 0}+Y_{S, 0}=k \times E C_{0}^{\frac{1}{\mu}}
$$


By combining Equations (12) and (13), $k$ can be removed, such that the expression for the shadow GDP $\left(Y_{S, t}\right)$ for any year $t$ reads as:

$$
Y_{S, t}=\left(Y_{O, 0}+Y_{S, 0}\right)\left(\frac{E C_{t}}{E C_{0}}\right)^{\frac{1}{\mu}}-Y_{O, t}
$$

To ease the comparison of the KK1996 results with the other methodologies used in this article, we calculate the weight of the shadow economy in relation to the official GDP as:

$$
\frac{Y_{S, t}}{Y_{O, t}}=\frac{\left(Y_{O, 0}+Y_{S, 0}\right)}{Y_{O, t}}\left(\frac{E C_{t}}{E C_{0}}\right)^{\frac{1}{\mu}}-1
$$

Equation (15) shows that the key parameter for determining the size of the shadow economy is $\phi$. In line with KK1996, in our first scenario we assume a unitary elasticity, $\phi=1$, which is consistent with the view that the factors that can generate upward or downward biases cancel each other out. Assuming an initial condition for $\frac{Y_{S, 0}}{Y_{O, t}}$ (which is taken from the CDA-BMA) and using a novel database built upon primary sources such as (i) reports and historical statistics from the Ministry of Industry, (ii) the Regional Government of Navarre and (iii) Eurostat (see Appendix), allows us to estimate the electricity production since 1986. Then, Equation (15) is used to compute $\frac{Y_{S, t}}{Y_{O, t}}$ in different periods. ${ }^{12}$

As an alternative to the assumption of a unitary and constant elasticity, $\phi=1$, we estimate this key parameter from an ordinary least squares (OLS) regression and use the relationship in Equation (15) to obtain estimates of $\widehat{\phi}$. The specification of the OLS model with fixed parameters is:

$$
\ln Y_{t}=\alpha+\phi \ln E L_{t}+\sum_{k} \beta_{k} X_{k, t}+\epsilon_{t}
$$

where $\ln Y_{t}$ is the logarithm of GDP; $\ln E C_{t}$ is the logarithm of the electricity consumed at time $t ; \widehat{\phi}=\frac{1}{\hat{\mu}}$ is potentially different from 1 and assumed to be constant over time; and $\mathbf{X}$ is a matrix of control variables that could affect both electricity consumption and production and whose omission could bias the estimation of $\phi$. The control variables included in $\mathbf{X}$ are: (i) a linear time trend; (ii) the weight of industrial employment in total employment; (iii) the price of electricity; (iv) the logarithm of the years of education; (v) the international price of oil (approximated by Brent barrel data); and, in dynamic versions of the model, (vi) the time lag of the logarithm of the output (i.e. GDP in $t-1$ ).

The reasons for introducing these controls draw from the literature in energy economics and development economics, showing that these factors correlate with either income and/ or electricity consumption. For instance, education is considered a relevant determinant of income, exerting a non-linear effect (Delgado et al., 2014). Second, crude oil is a crucial input and there is a broad consensus that higher oil prices affect both economic performance (Hamilton, 2009; Jones et al., 2004) and purchasing power. Similarly, electricity prices ac- 
count for an important share of the cost of goods and services driving the competitiveness of regions, which in turn matters for output growth (Schwab, 2018). Furthermore, there is empirical evidence of a link between electricity prices, oil prices and income (Shahbaz et al., 2017). Taken together, these arguments suggest the need to extend the simple framework of KK1996 and that of Novkovska and Novivksi (2018).

In particular, we consider the possibility that the elasticity of GDP to electricity consumption changes over time, as in Lee and Chiu (2011). Johnson et al. (1997), Schneider (2011), Schneider and Buehn (2017) and Novkovska and Novkovski (2018) have all suggested that neglecting the potential temporal variability of $\phi_{t}$ may affect the quality of the estimates. However, as far as we know, this is the first empirical analysis to produce estimates of the ratio of the shadow economy incorporating TVP model estimates of $\widehat{\phi}_{t}$. Under this scenario and starting from an initial condition $\frac{Y_{S, 0}}{Y_{O, t}}$, the time series of the ratio of the shadow economy $\left(Y_{S, t}\right)$ with respect to the official GDP $\left(Y_{O, t}\right)$ can be obtained recursively for each $t$ $(t=1986, \ldots, 2016)$ as:

$$
S E_{t}=\frac{Y_{S, t}}{Y_{O, t}}=\frac{Y_{T, t-} Y_{O, t}}{Y_{O, t}}
$$

where $Y_{T, t}$ and $Y_{O, t}$ have been previously normalized and where the estimate of the evolution of total economic activity $Y_{T, t}$ is given by:

$$
Y_{T, t}=Y_{T, t-1}\left(1+g_{E, t} \widehat{\phi_{t}}\right)
$$

where $g_{E, t}$ is the growth rate of electricity consumption. To obtain an estimate of $\widehat{\phi}_{t}$ and plug it into Equation (18), we estimate a TVP model using the Kalman filter algorithm described by Raftery et al. (2010) for state-space models. In particular, we estimate following the TVP model:

$$
\ln Y_{t}=\alpha_{t}+\phi_{t} \ln E L_{t}+\sum_{k} \beta_{t}^{(k)} X_{k, t}+\epsilon_{t}
$$

which is similar to the one based on fixed parameters in terms of the regressors included. However, a difference from Equation (19) with respect to the specification in Equation (16) is that a linear time trend is not included, because the parameters estimated in these models already contain temporal variability and the term $\alpha_{t}$ allows us to capture unobservable temporal heterogeneity. In particular, the TVP model is estimated using its state-space form representation given by:

$$
\begin{aligned}
& y_{t}=X_{t}^{\prime} \theta_{t}+\epsilon_{t}, \epsilon_{t} \sim N\left(0, V_{t}\right) \\
& \theta_{t}=\theta_{t-1}+\eta_{t}, \eta_{t} \sim N\left(0, W_{t}\right)
\end{aligned}
$$

where $y_{t}$ and $X_{t}$ are the dependent and explanatory variables, $\theta_{t}$ are the parameters, $\epsilon_{t}$ and $\eta_{t}$ are innovations and the conditional variances $V_{t}$ and $W_{t}$ are unknown quantities. Following Raftery et al. (2010) to speed up calculations and avoid the simulation of $W_{t}$, we set $W_{t}=$ $\left(1-\lambda^{-1}\right) \Sigma_{t}$, where $\Sigma_{t}$ is the covariance of $\theta_{t}$, which at $t=0$ is set to be diffuse. ${ }^{13}$ An important 
advantage of the previous TVP specification is that it helps capture non-linearities and threshold effects on the link between electricity consumption and income, which have been shown to be relevant in the energy economics literature (see Lee and Chiu, 2011).

\subsubsection{Results}

The results of the fixed-parameter regressions and various configurations of the TVP model, which provide us with the estimates of $\phi$ needed to calculate the shadow economy, are shown in Tables A3 and A4 in the Appendix. Again, here we merely note the main point: fixed-parameter models provide very low estimates of $\phi$ (in the range of $0.71 \%$ to $0.84 \%$ for static specifications and $0.66-0.82 \%$ in dynamic ones) when compared to those of the TVP model, which vary over time in the $0.88-0.97 \%$ range depending on the specific date. As shown in Figure 7, these differences have important consequences for the implied size of the shadow economy. The use of a unitary and constant elasticity over time gives larger values for the size of the shadow GDP relative to that of the TVP model, but the use of the elasticity stemming from fixed-parameter models generates lower values of the shadow GDP.

Figure 7

KAUFMANN AND KALIBERDA METHOD: SHADOW ECONOMY SIZE (as \% of GDP)

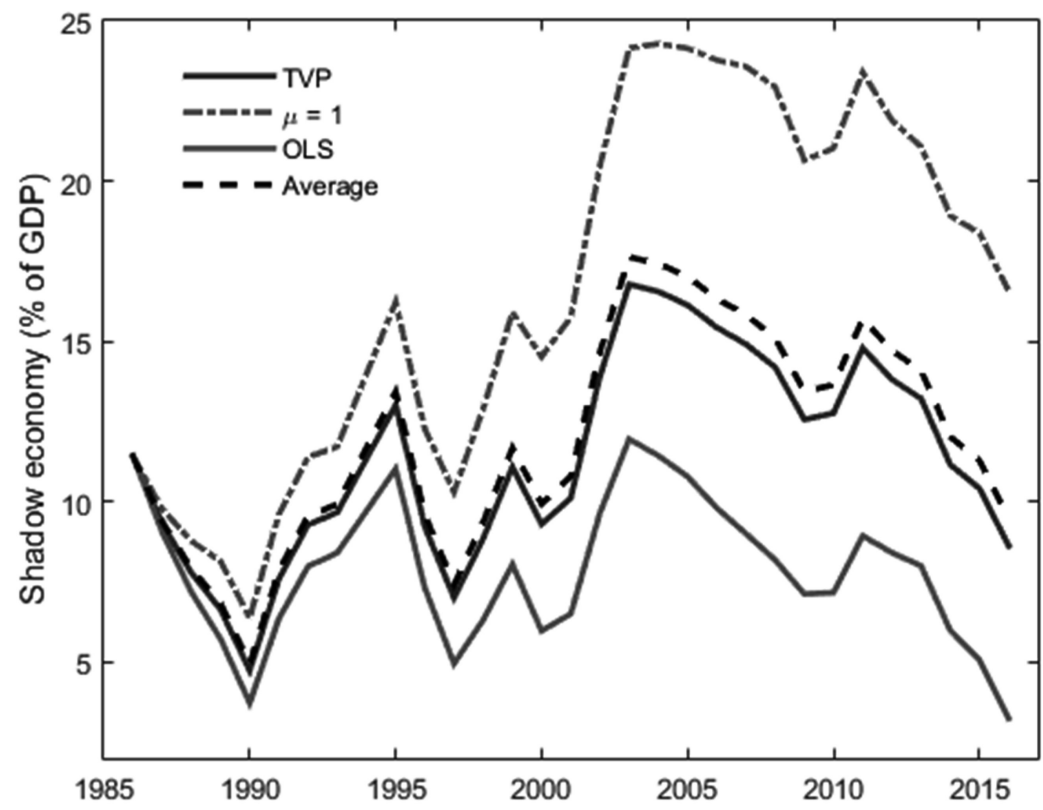

The estimate based on TVP suggests a slight reduction in the shadow economy during the period under study, from $11.42 \%$ in 1986 to $9.48 \%$ in 2016 . The classical assumption of a unitary elasticity would imply a considerable increase, reaching $16.57 \%$ in 2016 , while the OLS regressions would imply a strong decrease of up to $3.24 \%$ in 2016 . Looking at the 
average trajectory shown in Figure 7, our findings suggest an erratic pattern of the ratio of the shadow economy to GDP between 1986 and 2003, with strong oscillations. However, from 2003 to 2016 the shadow economy ratio seemed to decrease, with a rebound in 2010 and 2011. The average size across the three alternatives in this context is $11.94 \%$ and the overall time profile is that of an inverted $\mathrm{U}$, although it is less clear than the one arising from the estimation of the CDA-BMA.

\subsection{The Lackó Approach}

This method also estimates the size of the shadow economy based on domestic electricity consumption. It assumes that the shadow economy is present in all sectors -including households- and that a portion of household electricity consumption is used for hidden activities. Lackó's $(1996,1998,2000)$ method proposes the estimation of a model in which electricity consumption is explained as a function of different determinants.

The method assumes that household electricity consumption is not only determined by visible factors such as (i) the size of the population, (ii) the level of development, (iii) the climatic characteristics, (iv) the relative price of electricity and (v) access to other energy sources, but also by the size of the shadow economy. A second assumption is related to the role of taxes and the tax burden. The intuition is again similar to that of the CDA: increases in the tax burden are assumed to stimulate economic agents to migrate to the shadow economy. Furthermore, the Lackó approach considers that high percentages of inactive or unemployed people (e.g. during an economic crisis) represent a greater potential workforce who can be employed in the hidden sector.

However, Lackó's approach provides a direct estimate not of the size of the shadow economy, but of the amount of total energy consumed that can be attributed to hidden activities. Therefore, to obtain an estimate of the size of the shadow economy with this approach, additional information on energy productivity in the hidden sector is required. After running the corresponding electricity consumption regressions, one needs to assume how much shadow GDP is produced per unit of energy employed to carry out hidden activities. Unfortunately, this implies making heroic assumptions, because such information does not exist.

\subsubsection{Data and Methodology}

The regression framework inspired by the seminal work of Lackó $(1996,1998,2000)$ is given by:

$$
E C_{t}=\alpha+\sum_{k=1}^{K} \beta_{k} H_{t, k}+\sum_{q=1}^{Q} \delta_{q} X_{t, q}+\varepsilon_{t}
$$

where the dependent variable $E C_{t}=\ln \frac{E C N_{t}}{P E_{t}}$ is a vector of observations of the logarithm of real electricity consumption (where $E C N_{t}$ is the nominal consumption of energy and $P E_{t}$ 
is the energy deflator) and $H_{t, k}$ is a matrix of variables determining the size of the shadow economy.

The variables included in $\boldsymbol{H}$ refer to: (i) the unemployment rate; (ii) the inflation rate; (iii) a dummy that takes a value of 1 if the economy is in recession and 0 otherwise; (iv) the income tax burden (in \% of GDP); (v) the corporate tax burden (in \% of GDP); and (vi) the total tax burden including social contributions (in \% of GDP). The inclusion of these variables is justified because an increase in them will encourage economic agents to leave the official sector; see Lackó (1996, 1998, 2000) for a detailed discussion.

The factors included in a matrix $\boldsymbol{X}$ refer to (i) socio-demographic factors such as the logarithm of the population, the average years of education and the net migratory balance. We control for these variables given that the existing evidence points to a negative link between education and electricity consumption (Gill and Lang, 2018) and a positive effect of population variables on electricity consumption, because a larger population size will increase electricity consumption (Blázquez-Gómez et al., 2013).

In addition, we include (ii) controls related to economic evolution and production structure, such as the logarithm of real GDP, the price of oil and the percentage of employment in agriculture, industry, construction, non-market and financial services. The level of GDP and the specific sectoral composition at a given point in time are likely to have an impact on electricity consumption patterns (Blázquez-Gómez et al., 2013; Lee and Chiu, 2011; Stern, 2019). On the one hand, increasing output expands the demand for electricity. On the other hand, each sector has a different electricity intensity, so there is a composition effect, which may also be influenced by technological progress and its impact on the energy efficiency. As regards oil prices, the evidence is rather weak (see Bosco et al., 2010; Mohammadi, 2009), but because a significant proportion of the electricity produced is generated using fossil fuels, it seems prudent to control for oil prices in this context.

Finally, $X_{t, q}$ incorporates (iii) climatic and temporal factors such as the linear and quadratic temporal trend, the annual average temperature and the coefficients of variation of the maximum and minimum temperatures, which may correlate with the household electricity consumption needed for heating. Controlling for climatic factors is important in this context as there is evidence that higher average temperatures reduce the need for electricity consumption (Ang et al., 2017; Hor et al., 2005; Lee and Chiu, 2011), whereas extreme weather events increase it (Hor et al., 2005).

In sum, this analysis includes twenty potential predictors and employs the BMA estimation algorithm ${ }^{14}$ in order to account for model uncertainty and solve the potential econometric problems previously discussed within the CDA framework. The factors in $\mathbf{H}$ are always part of the model, whereas the factors in $\mathbf{X}$ are not fixed in the sampling of models.

The estimation algorithm in this modified Lackó-BMA framework is summarized in the following four steps:

1. Estimation of Equation (20) using the BMA methodology to produce estimates of $\widehat{E C}_{t}$. 
2. Estimation of the demand for electricity if the determinants in $H_{t, k}$ were zero or had not changed since 1986: $\widehat{E C_{C, t}}\left(\widehat{\beta_{k}}=0, \forall k\right)$.

3. Estimation of the electricity consumption attributed to hidden economic activities:

$$
\widehat{E C_{S, t}}=\exp \widehat{E C_{t}}-\exp \widehat{E C_{C, t}}\left(\widehat{\beta_{k}}=0\right)
$$

4. Transformation of electricity consumption data into a series of shadow GDP:

$$
\widehat{Y_{S, t}}=r \times \widehat{E C_{S, t}} \times E P
$$

where $r$ is a parameter that measures the level of productivity or efficiency of the hidden sector with respect to the official sector and $E P$ is the energy productivity $\frac{Y_{O, t}}{E_{O, t}}$. Finally, compute $S E_{t}=\frac{Y_{S, t}}{Y_{O, t}}$.

\subsubsection{Results}

Similarly to the CDA-BMA, the implementation of the Lackó-BMA here combines the information provided by the $\mathrm{MC}^{3}$ sampler with additional model restrictions, such that the model space employed to draw inferences is restricted to the models that satisfy (i) that the initial shadow economy estimates are within $0 \% \leq \frac{Y_{S, 0}}{Y_{O, 0}} \leq 50 \%$ and (ii) that the last period value is positive, i.e. $\frac{Y_{S, T}}{Y_{O, T}} \geq 0 \%$.

Table A5 in the Appendix shows the results of the Lackó-BMA. Here we note the main findings. Lackó (2000) conjectured that all tax variables (with the exception of public spending, which is not included here) would have a positive impact and that the same would happen with the inflation rate and the dummy capturing crisis periods. Nevertheless, only income taxes and the overall tax burden seem to exert a positive effect on electric consumption (although the total burden does not seem to be significant). Regarding the remaining variables in $H_{t, k}$, we find that inflation and unemployment seem to have a positive effect on taxation (although these effects are not statistically significant in many of the models sampled). The dummy capturing crisis periods and the corporate tax indicators exert a negative effect, but only the latter tend to be significant. Therefore, the results of the Lackó-BMA provide only partial support for the hypotheses of Lackó $(1996,1998,2000)$ in their application to the economy of Navarre.

In any case, with the $\widehat{E C}_{t}$ model-average estimates in hand, we perform the counterfactual analysis by shutting down the parameters of the factors in $\mathbf{H}$ to obtain the demand for electricity if the determinants in $H_{t, k}$ were zero (or had not changed since 1986). The results are provided in Figure 8, where we plot three series: the observed path of the logarithm of electricity consumption, the estimated model with all factors $\left(\widehat{E C}_{t}\right)$ and the counterfactual path $\widehat{E C_{C, t}}$. The latter two values are used in the third step, from which we obtain the elec- 
tricity demand for hidden activities, $\widehat{E C_{S, t}}$. Our findings reveal that this magnitude increased considerably from 1986 to 2005, when the peak electricity consumption for hidden activities was reached, achieving the $536,000 \mathrm{mWh}$ threshold. It then experienced a downturn until 2009 with a minimum of 313,000 mWh, bounced back during 2010 and fell again until 2012. Finally, in the period 2013-2016 it increased again, reaching an annual hidden electricity consumption level of 424,000 $\mathrm{mWh}$.

Figure 8

LACKÓ METHOD: ELECTRIC CONSUMPTION

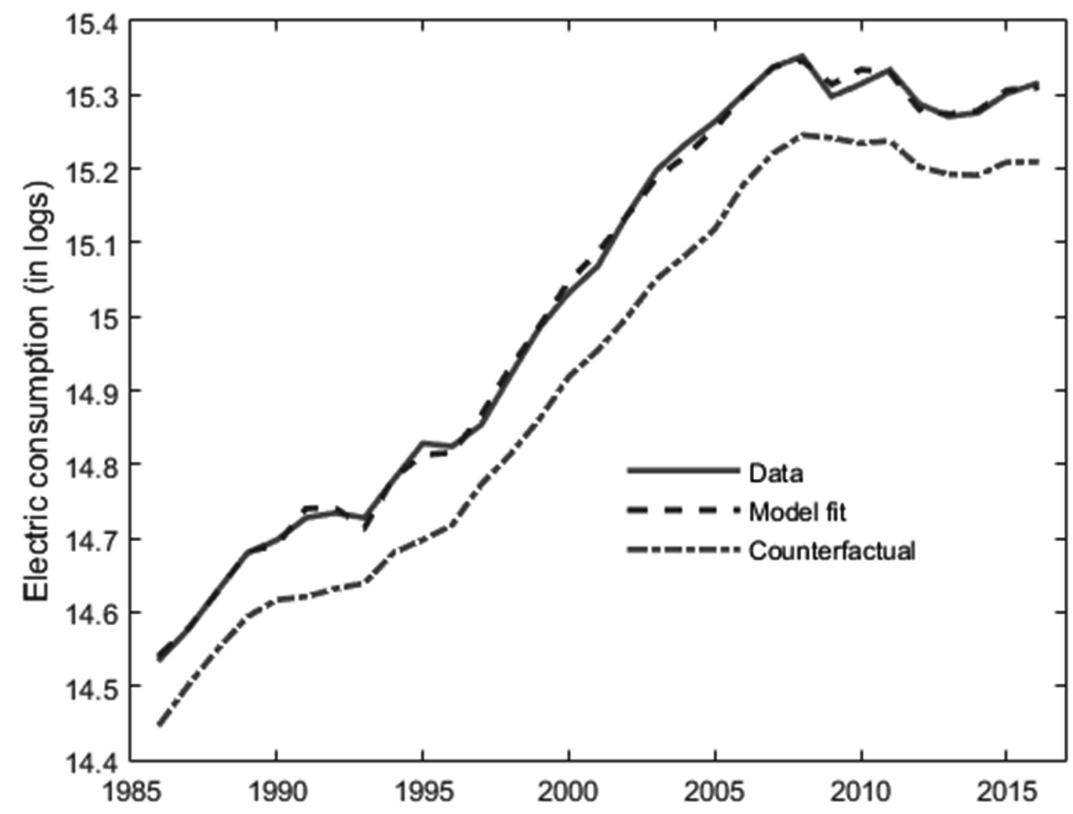

As explained before, to proceed further, we need to set a value for $r$, the parameter that measures the relative productivity or efficiency of the hidden sector with respect to the official sector. Researchers such as Novkovska and Novkovski (2018) consider that the energy efficiency of the hidden sector is lower than that of the official sector. However, this conjecture is controversial, because the informal sector includes many legal activities (such as domestic or personal care) or illegal activities (such as drug sales, prostitution or illegal gambling) that require low energy consumption in relation to their value added. Thus, to generate scenarios compatible with a higher energy productivity hypothesis in the shadow economy sector, we set $r=1.25$ and transform the time series of $\mathrm{mWh}$ into euros using the time series of energy efficiency or energy productivity, which in Navarre was about $€ 4.24$ during the period 1986-2016. ${ }^{15}$

The size of the shadow economy that stems from this procedure is shown in Figure 9, together with the average of the KK1996 results. The estimation based on the Lackó-BMA ap- 
proach points to a ratio of the shadow economy to GDP that has an average value of $9.9 \%$ for the period 1986-2016, lower than the $11.93 \%$ average in the KK1996 approach. The temporal path is very similar to that of KK1996, with a sharper inverted U pattern and a peak in 2003. In the time interval 1986-1997, the Lackó-BMA approach predicts an alternation of ups and downs, with a subsequent rise until 2003. From 2004 to 2009, the size of the hidden sector drops sharply to $7.37 \%$ of the GDP. The $2010-2012$ period is characterized by oscillations and from 2013 to 2016 there is a new increase from $8.1 \%$ to $9.49 \%$ of the GDP, which is practically the same value as that of KK1996. Nonetheless, a difference with respect to KK1996 is that in recent years our Lackó-BMA approach predicts a rebound, rather than a reduction.

Figure 9

ESTIMATIONS: KAUFMANN AND KALIBERDA VS. LACKÓ

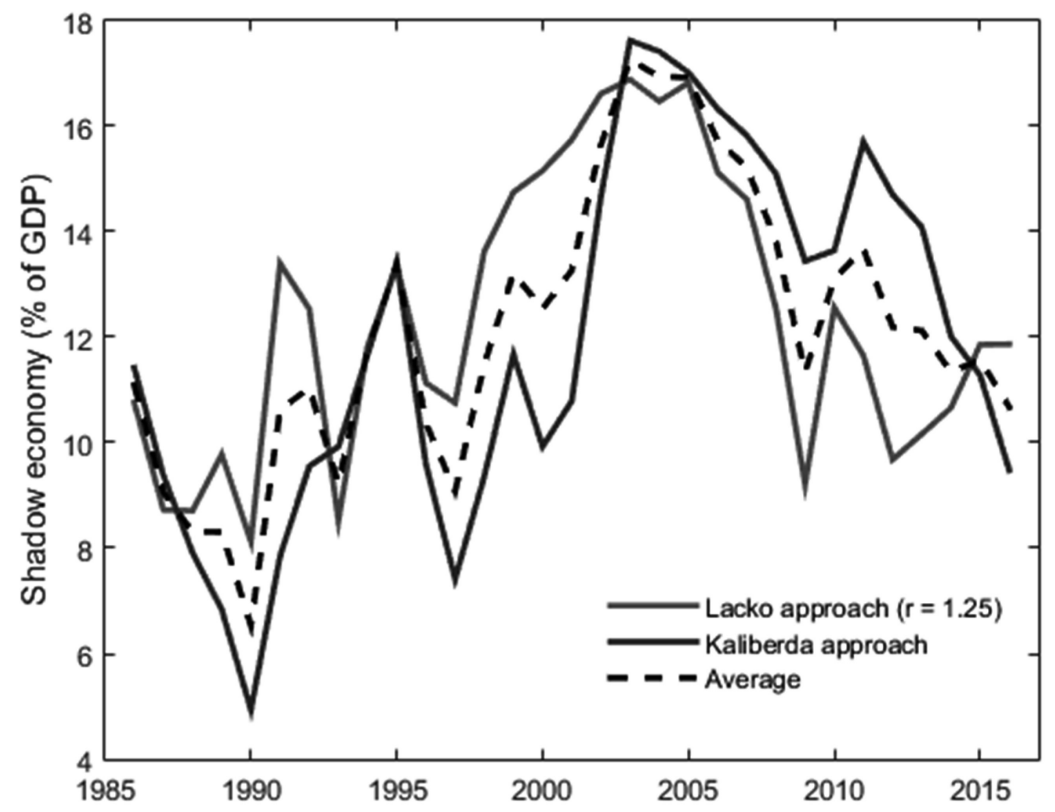

\section{The MIMIC Approach}

The MIMIC approach explicitly considers multiple causes of the existence of the shadow economy as well as its potential effects on multiple indicators over time. MIMIC models specify a factor and a structural model simultaneously. Using covariance information on observable variables, the unobservable variable (i.e. the shadow economy) is linked to observable variables in a factor analytical model. Furthermore, relationships between the unobservable variable and the observable variables are specified through a structural model. In this sense, the MIMIC model tests the consistency of a 'structural' theory by examining if the hypothesized relationships between the unobservable latent factor and the observable var- 
iables are supported by the data (Schneider and Buhen, 2017). The MIMIC was introduced by Frey and Weck (1983) and Frey and Weck-Hannemann (1984) and since then, it has been employed by many scholars, such as Giles (1999a, 1999b), Giles and Tedds (2002), Schneider (2005), Dell'Anno and Schneider (2009) and Schneider et al. (2010).

The key benefits of the MIMIC model are that it allows shadow economy activities to be modelled as an unobservable (latent) variable and it accounts for multiple determinants (causes) and multiple effects (indicators). According to Giles and Tedds (2002), it takes into consideration more indicators and more causes than most alternative measurement approaches, which in turn reduces the risk of underestimating the true size of the shadow economy.

However, this approach also has limitations (Feige, 2016a, 2016b). The most common objection is that the latent variable may capture other phenomena different from that of the shadow economy (Dell'Anno, 2003; Helberger and Knepel, 1988). Another criticism is that MIMIC estimates often lead to unstable coefficients with respect to changes in sample size and alternative model specifications (Helberger and Knepel, 1988). In addition, the MIMIC approach requires estimates of another exogenous method of measurement to calibrate the latent variable, given that the output of the MIMIC estimation is an unscaled index that shows the dynamics of the latent factor. Finally, many researchers criticize the procedures used to calibrate the shadow economy from the latent variable index (i.e. its conversion into monetary units or into a percentage of GDP) because they are quite ad hoc. ${ }^{16}$ An additional problem is that of distinguishing between causes and indicators. These weaknesses call for caution, so we present the results of this approach with the aim of complementing the previous two methods by introducing two novel calibration procedures.

\subsection{The MIMIC Model}

The MIMIC model is a special case of a structural equation model (SEM) that relates time series of observed variables or causes to an unobserved latent variable (the shadow economy) by means of a 'factor model' whose evolution and development affect a different set of variables or indicators. Giles and Tedds (2002) describe the MIMIC model as a relationship between a matrix of indicators $y_{t}$ of size $T x P$ and a matrix of causes $X_{t}$ of size $T x Q$ connected by means of a latent variable $\eta_{t}$ of size $T x 1$, which measures the shadow economy at each point in time. This latent variable $\eta_{t}$ is determined by a set of observable causes $X_{t}$, while $\gamma$ is a $Q \times 1$ vector of structural parameters such that:

$$
\eta_{t}=X_{t} \gamma+\zeta_{t} \quad \zeta_{t} \sim N\left(0, \sigma^{2}\right)
$$

The latent variable $\eta_{t}$, in turn, determines a set of endogenous indicators $y_{t}$ :

$$
y_{t}=\eta_{t} \lambda+\epsilon_{t} \quad \epsilon_{t} \sim N\left(0, \Theta^{2}\right)
$$

where $\lambda$ is a $P x 1$ vector and $\epsilon_{t}$ and $\zeta_{t}$ are random error terms of size $T x P$ and $T x 1$, respectively, which follow zero mean normal distributions with variances given by $E\left(\zeta \zeta^{\prime}\right)=\sigma^{2}$ and $E\left(\epsilon \epsilon^{\prime}\right)=\Theta^{2}$, which are not correlated with each other (i.e. $E\left(\zeta \epsilon^{\prime}\right)=0$ ). Substituting (24) into 
(25) yields a reduced form equation which expresses the relationships between the observed causes and indicators, that is, between $X_{t}$ and $y_{t}$. This is shown in Equation (26)

$$
y_{t}=\Pi X_{t}+z_{t} \quad z_{t} \sim N\left(\lambda \zeta_{t}+\epsilon_{t}, \lambda \Theta^{2} \lambda^{\prime}+\sigma^{2}\right)
$$

where $z_{t}$ is a reduced form vector of a linear transformation of disturbances and $\Pi=\lambda \gamma$.

Contrary to standard econometrics, instead of minimizing the distance between observed and predicted individual values, the MIMIC approach minimizes the distance between an observed (sample) covariance matrix $S$ and the covariance matrix predicted by the theoretical model the researcher imposes on the data $\Sigma(\theta)$, where $\theta=\left(\lambda, \gamma, \sigma^{2}, \Theta^{2}\right)$ are the model parameters. An issue is that the number of parameters in the reduced form expression is higher than that of the structural model, which requires fixing $\eta_{t}$ for identification purposes. We follow the convention of setting the first element of $\lambda$ as either -1 or 1 and check if after this scaling the sign of the other coefficients makes sense (see Dell'Anno, 2003). ${ }^{17}$

\subsection{Data on Causes and Indicators}

We now describe the variables included in our analysis as causes: (i) the tax burden; (ii) institutional quality; (iii) the unemployment rate; and (iv) the share of total employment in the construction sector.

The overall tax burden is the most widely accepted and important cause (Johnson et al., 1997, 1998; Tanzi, 1999) and is measured by the ratio of total tax revenue (including social contributions) to GDP. As a robustness check, this indicator has also been disaggregated into different partial proxies such as direct taxes, indirect taxes, social contributions and total taxes (excluding social contributions), always in \% of the GDP, with the aim of verifying whether all the components of the aggregate tax burden have the same impact on the shadow economy.

Following Schneider (2010), we include the evolution in the quality of institutions, as this is likely to affect people's incentives to operate in the shadow economy. To approximate the evolution in the quality of institutions in Navarre, we employ a composite index, calculated as the arithmetic average of three normalized national-level corruption indicators drawn from three databases: the World Governance Indicators (WGI), the Varieties of Democracies Database (VDEM) and the International Country Risk Guide (ICRG).

The unemployment rate is also expected to affect our latent variable. The most widely accepted hypothesis is that an increase in unemployment leads to an increase in hidden activities, because unemployed people have a greater incentive to find a job in the informal economy (see Schneider et al., 2010). However, it has also been argued that the availability of informal jobs becomes limited when there is a contraction in the general economy and when unemployment is high, because the availability of jobs, whether formal or informal, decreases. In fact, Alañón and Gómez-Antonio (2005) and Macias and Cazzavillan (2010) have found a negative effect. 
Typically, MIMIC studies find that the productive structure matters for the size of the shadow economy. Some authors have used employment in the public sector (Dell'Anno, 2003; Tafenau et al., 2010), the share of the agricultural sector (Hassan and Schenider, 2016a, 2016b) or the percentage of self-employed people in the total employed population (Dell'Anno, 2007). However, given that Schneider's (2013) estimates for Spain suggest that the construction sector has historically had greater informality than its counterparts, we use the share of employment in the construction sector.

The indicators in $y_{t}$ that are assumed to capture the effects of variations in the size of the shadow economy are (i) the growth rate of real GDP and (ii) the growth rate of currency in real terms. ${ }^{18}$ For example, Schneider et al. (2010) for 114 countries, Loayza (1996) for fourteen Latin American countries and Dell'Anno et al. (2007) for France, Greece and Spain have all concluded that there is a negative relationship between the size of the shadow economy and the size of the official economy. Thus, we establish the real GDP index growth rate as our reference variable, expecting it to have a negative sign (i.e. we set $\lambda_{1}=-1$ ). As regards the growth rate or real currency, we expect a positive correlation in line with our findings in the CDA-BMA.

\subsection{Calibration}

Following Dell'Anno et al. (2007), all the variables are pre-processed by means of a standardization procedure (i.e. $\widetilde{X_{t}}=\frac{X_{t}-\bar{X}}{\sigma_{x}}$ and $\widetilde{y_{t}}=\frac{y_{t}-\bar{y}}{\sigma_{y}}$ ) to avoid numerical problems in the MIMIC estimation. Given that the question of how to normalize and calibrate the latent indicator is not well-established in the literature, we exploit this data pre-processing step to implement a novel calibration of the latent indicator subsequently.

In our empirical application we standardize both variables $\left(\widetilde{y_{t}}, \widetilde{X_{t}}\right)$ so that they have a zero mean and are expressed as standard deviations. Thus, the latent indicator obtained after the MIMIC estimation informs us on how fluctuations around the mean of 'the causes' are mapped into deviations around the mean of 'the indicators'. For this reason, the most plausible interpretation for this latent indicator is that of standard deviations (with respect to the average) of the ratio of the shadow economy to GDP. The two calibration strategies employed in this analysis are linked to this interpretation.

Our first strategy to transform the latent indicator into a ratio of the shadow economy to GDP for each t requires: (i) an initial estimate for $\left(\frac{\eta}{G D P}\right)_{\bar{b}}^{*}$ in 1986 consistent with the Currency Demand method (equal to 0.114); and (ii) the estimate of the standard deviation of the estimated series using the Currency Demand method $\widehat{\sigma^{*}}=\operatorname{std}\left(\frac{\eta}{G D P}\right)^{*}=0.0279$. Equation (27) shows the benchmarking used:

$$
S E_{t}^{M I M I C}=\left(\frac{\eta}{G D P}\right)_{\bar{b}}^{*}+\left(\hat{\eta}_{t}+c\right) \widehat{\sigma}^{*}
$$


where $S E_{t}^{\text {MIMIC }}$ is the period $t$ estimate of the shadow economy as a percentage of GDP arising from the MIMIC approach after calibration, $\hat{\eta}_{t}$ is the value of the unscaled index capturing fluctuations in the shadow economy and $c$ is a constant chosen to satisfy the calibration requirement that the estimate of the MIMIC in the base period coincides with that of the CDA, such that $S E_{b}^{M I M I C}=\left(\frac{\eta}{G D P}\right)_{\bar{b}}^{*}$.

As an alternative, we use a multiplicative calibration procedure inspired by Giles and Tedds (2002), who propose the following benchmarking:

$$
S E_{t}^{\text {MIMIC }}=\left(\frac{\eta}{G D P}\right)_{t}^{\text {final }}=\mu\left(\frac{\eta}{G D P}\right)_{t}^{o}
$$

where $\mu=\frac{\left(\frac{\eta}{G D P}\right)_{\bar{b}}^{*}}{\left(\frac{\eta}{G D P}\right)_{\bar{b}}^{O}}$ is a constant that is multiplied by the estimated latent index in order to satisfy the condition that the shadow economy as a percentage of official GDP in the base period is equal to the value obtained by an exogenous method. Following this idea, we introduce an additional adjustment parameter $\mu_{2}$ so that the time series not only replicates the value of the shadow economy as a percentage of the official GDP in the base period obtained by an exogenous method, but also has the same time average of the exogenous method under consideration (even if it has a different dynamic of its own, implied by the evolution of $\hat{\eta}_{t}$ ). Specifically, this second calibration consists of choosing two constants $\mu_{1}$ and $\mu_{2}$ that satisfy the equations:

$$
\begin{gathered}
S E_{b}^{M I M I C}=E S_{b}^{C D A}=\mu_{1}\left[\left(\frac{\eta_{b}}{P I B}\right)_{b}^{O}+\mu_{2}\right] \\
S E^{C D A}=\frac{1}{T} \sum_{t=1}^{T} \mu_{1}\left[\left(\frac{\eta_{t}}{P I B}\right)_{t}^{O}+\mu_{2}\right]
\end{gathered}
$$

We use this modified procedure inspired by Giles and Tedds (2002) and Tedds (2005), so that the estimation matches not only the base period of the CDA but also its time series average.

\subsection{Results}

The MIMIC model results are presented in Table 1, which is divided into three parts. The first part shows the results of the causal variables of the shadow economy. The second part shows the indicators of the shadow economy. The third part includes statistics indicative of goodness of fit.

Regarding the causes, we find that the tax burden indicators are statistically significant for all the models where they are included (except for indirect taxes) and display the expected sign. Social contributions exert the greatest impact on the latent indicator. On the other hand and in line with previous results from the literature, direct taxes appear to be more 
relevant than indirect taxes in explaining the fluctuations in the size of the shadow economy (see Models III and IV). The unemployment rate, in general, has a negative and statistically significant effect. This suggests that in Navarre, the contractions of aggregate demand reduce the possibilities of finding a job in the hidden sector, which is in line with the results for Spain estimated by Alañón and Gómez-Antonio (2005). The effect of institutional quality is negative in most models, as predicted by theory, but in general it is not significant. Finally, the share of the construction sector in total employment stands out as the most relevant of the causes considered, with the highest coefficient among all the indicators. Models VI and VII include inflation and the percentage of employment in non-market services (mainly public employment) as causes of the shadow economy, but they are not significant. However, in these specifications both the tax burden and construction maintain their effects.

Table 1

MIMIC model: Results

\begin{tabular}{|c|c|c|c|c|c|c|c|}
\hline Variables & $\begin{array}{l}\text { Model } \\
\text { (I) }\end{array}$ & $\begin{array}{c}\text { Model } \\
\text { (II) }\end{array}$ & $\begin{array}{c}\text { Model } \\
\text { (III) }\end{array}$ & $\begin{array}{c}\text { Model } \\
\text { (IV) }\end{array}$ & $\begin{array}{c}\text { Model } \\
\text { (V) }\end{array}$ & $\begin{array}{c}\text { Model } \\
\text { (VI) }\end{array}$ & $\begin{array}{c}\text { Model } \\
\text { (VII) }\end{array}$ \\
\hline \multicolumn{8}{|l|}{ Causes } \\
\hline $\begin{array}{l}\text { Total tax burden (inc. Soc. } \\
\text { Contrib.) }\end{array}$ & $\begin{array}{l}0.337^{* * *} \\
(3.99)\end{array}$ & & & & & & \\
\hline Social Contributions burden & & $\begin{array}{l}0.594^{* * *} \\
(3.11)\end{array}$ & & & & & \\
\hline Direct taxes burden & & & $\begin{array}{l}0.152^{* * *} \\
(3.69)\end{array}$ & & & & \\
\hline Indirect taxes burden & & & & $\begin{array}{c}0.188 \\
(1.17)\end{array}$ & & & \\
\hline $\begin{array}{l}\text { Total tax burden (exc. Soc. } \\
\text { Contrib.) }\end{array}$ & & & & & $\begin{array}{l}0.354^{* * *} \\
(2.53)\end{array}$ & $\begin{array}{c}0.346^{*} \\
(1.72)\end{array}$ & $\begin{array}{c}0.222^{*} \\
(1.69)\end{array}$ \\
\hline Unemployment & $\begin{array}{l}-0.315^{* * *} \\
(-2.12)\end{array}$ & $\begin{array}{l}-0.244^{* * *} \\
(-2.46)\end{array}$ & $\begin{array}{l}-0.182^{* *} \\
(-2.18)\end{array}$ & $\begin{array}{l}-0.06 \\
(-0.31)\end{array}$ & $\begin{array}{l}-0.215 \\
(-1.18)\end{array}$ & $\begin{array}{l}-0.219^{* * *} \\
(-1.10)\end{array}$ & $\begin{array}{l}-0.216 \\
(-1.21)\end{array}$ \\
\hline Employment in construction & $\begin{array}{l}0.834^{* * *} \\
(3.71)\end{array}$ & $\begin{array}{l}0.848^{* * *} \\
(3.05)\end{array}$ & $\begin{array}{l}0.668^{* * *} \\
(3.27)\end{array}$ & $\begin{array}{l}0.739^{* * * *} \\
(3.50)\end{array}$ & $\begin{array}{l}0.828^{* * *} \\
(3.94)\end{array}$ & $\begin{array}{c}0.826^{* * *} \\
(3.91)\end{array}$ & $\begin{array}{l}0.955^{* * *} \\
(3.76)\end{array}$ \\
\hline Institutional quality & $\begin{array}{l}-0.039 \\
(-0.34)\end{array}$ & $\begin{array}{r}-0.034 \\
(-0.57)\end{array}$ & $\begin{array}{l}-0.098^{*} \\
(-1.73)\end{array}$ & $\begin{array}{c}0.016 \\
(0.10)\end{array}$ & $\begin{array}{l}-0.033 \\
(-0.21)\end{array}$ & $\begin{array}{l}-0.033 \\
(-0.20)\end{array}$ & $\begin{array}{l}-0.018 \\
(-0.11)\end{array}$ \\
\hline $\begin{array}{l}\text { Employment in non-market } \\
\text { services }\end{array}$ & & & & & & $\begin{array}{c}0.013 \\
(0.051)\end{array}$ & \\
\hline Inflation & & & & & & & $\begin{array}{l}-0.234 \\
(-1.34)\end{array}$ \\
\hline \multicolumn{8}{|l|}{ Indicators } \\
\hline Real GDP growth & -1 & -1 & -1 & -1 & -1 & -1 & -1 \\
\hline Real currency growth & $\begin{array}{l}1.312^{* * *} \\
(4.42)\end{array}$ & $\begin{array}{l}1.88^{\text {**** }} \\
(3.13)\end{array}$ & $\begin{array}{l}0.809^{* * * *} \\
(4.09)\end{array}$ & $\begin{array}{l}1.644^{* * * *} \\
(3.73)\end{array}$ & $\begin{array}{l}0.864^{* * *} \\
(4.54)\end{array}$ & $\begin{array}{c}0.865^{* * * *} \\
(4.54)\end{array}$ & $\begin{array}{l}0.935^{* * *} \\
(4.80)\end{array}$ \\
\hline
\end{tabular}


(Continued)

\begin{tabular}{lccccccc}
\hline Variables & $\begin{array}{c}\text { Model } \\
\text { (I) }\end{array}$ & $\begin{array}{c}\text { Model } \\
(\mathbf{I I})\end{array}$ & $\begin{array}{c}\text { Model } \\
(\mathbf{I I I})\end{array}$ & $\begin{array}{c}\text { Model } \\
(\mathbf{I V})\end{array}$ & $\begin{array}{c}\text { Model } \\
(\mathbf{V})\end{array}$ & $\begin{array}{c}\text { Model } \\
(\text { VI) }\end{array}$ & $\begin{array}{c}\text { Model } \\
\text { (VII) }\end{array}$ \\
\hline Variances & & & & & & & \\
\hline Real GDP growth (y1) & 0.534 & 0.721 & 0.648 & 0.321 & 0.311 & 0.312 & 0.338 \\
$\mathrm{R}^{2}$ (y1) & 0.488 & 0.274 & 0.336 & 0.631 & 0.620 & 0.620 & 0.635 \\
Real currency growth (y2) & 0.222 & 0.099 & 0.105 & 0.544 & 0.478 & 0.477 & 0.418 \\
$\mathrm{R}^{2}$ (y2) & 0.711 & 0.850 & 0.865 & 0.562 & 0.583 & 0.583 & 0.574 \\
& 24.613 & 27.893 & 30.705 & 13.403 & 13.403 & 14.101 & 17.696 \\
p-values & 0.02 & 0.02 & 0.03 & 0.01 & 0.04 & 0.03 & 0.04 \\
RMSEA & 0.392 & 0.473 & 0.444 & 0.317 & 0.321 & 0.246 & 0.283 \\
p-values & 0.00 & 0.00 & 0.00 & 0.00 & 0.00 & 0.00 & 0.00 \\
RSMR & 0.163 & 0.220 & 0.173 & 0.116 & 0.121 & 0.11 & 0.116 \\
Comparative Fit Index (CFI) & 0.734 & 0.751 & 0.734 & 0.804 & 0.803 & 0.81 & 0.806 \\
\hline
\end{tabular}

Notes: All the variables are standarised so they enter the model as unitary standard deviations. ${ }^{*} 10 \%$ signif. ${ }^{* *} 5 \%$ signif. *** $10 \%$ signif. The statistic $\chi^{2}=(\mathrm{T}) \mathrm{F}_{\min }$ (where $\mathrm{T}$ is the sample size and $\mathrm{F}_{\min }$ is the minimum discrepancy between covariances $\Sigma$ and S) contrasts the null hypothesis that the model is correct. The statistic $C F I=\frac{1-\max \left[\left(\chi_{t}^{2}-d f_{t}\right) \cdot 0\right]}{\max \left[\left(\chi_{t}^{2}-d f_{t}\right) \cdot\left(\chi_{n}^{2}-d f_{n}\right) \cdot 0\right]}$ corrects the inference problems in when T is low. It moves between 0 and 1 so a value of 0.8 denotes that the specified model involves an improvement in the adjustment with respect to the null model of $80 \%$.

Regarding the indicators, the estimated effect of the shadow economy on the growth in real GDP is negative, while it has a significant positive effect on the growth in real currency, confirming that the normalization of $\lambda_{1}=-1$ is the most intuitive.

We present a variety of goodness of fit tests for SEMs. The $\chi_{2}$ test and the quadratic average of the Root Mean Square Error of Approximation (RMSEA) point to a relatively low-quality fit. However, this may be due to the small sample size: our time span is thirty-one years, whereas this statistic generally requires about one hundred observations to adequately discriminate between alternative models. Therefore, to assess the fit to the data, we use the comparative fit index (CFI), which is better suited for small samples. The CFI indicates that various specifications imply an improvement ranging from $73 \%$ to $81 \%$ with respect to the null model, in which it is assumed that the latent variable is independent of the causes. Therefore, the estimates are considered sufficiently good.

The evolution of the latent variable estimated for Models I to $\mathrm{V}$ is shown in Figure 10. As can be seen, regardless of the type of tax indicator used, the time pattern is quite similar. This reinforces the idea that different models identify the same latent variable. To carry out the calibration exercise, we use the average of the estimated latent factors in Models I to $\mathrm{V}$. 
Figure 10

MIMIC MODEL: ESTIMATION OF THE LATENT VARIABLE (Models I-V)

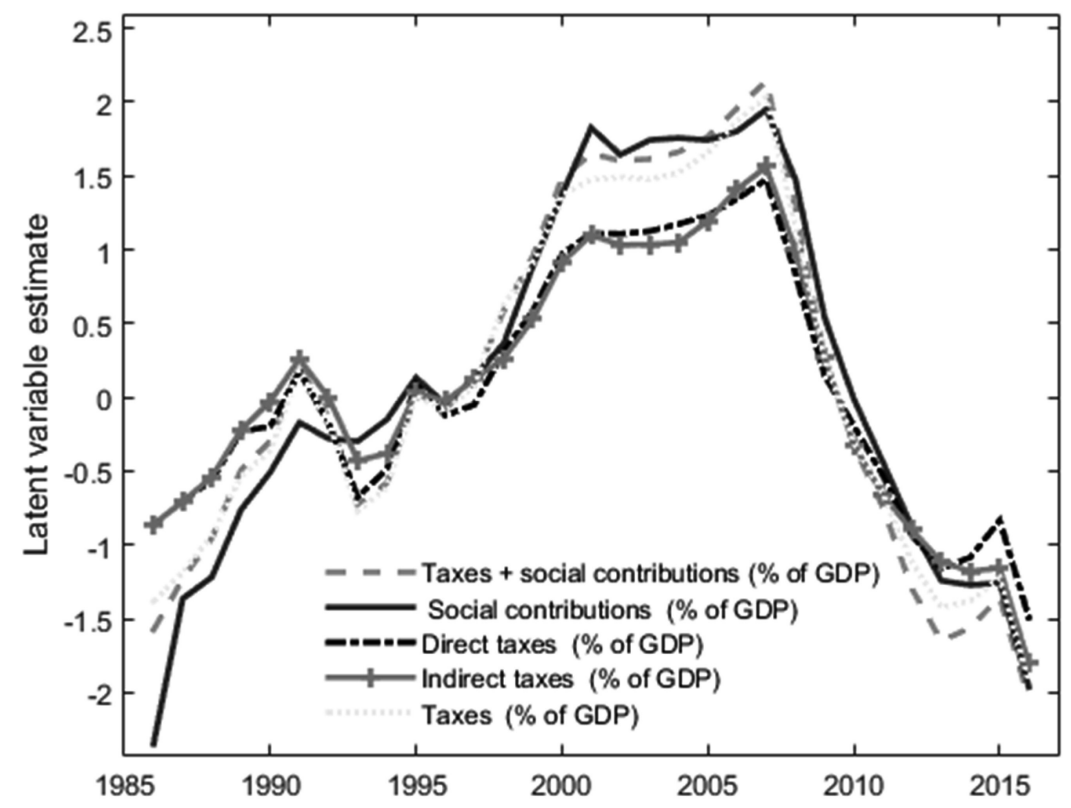

Figure 11

MIMIC MODEL: SHADOW ECONOMY SIZE (as \% of GDP)

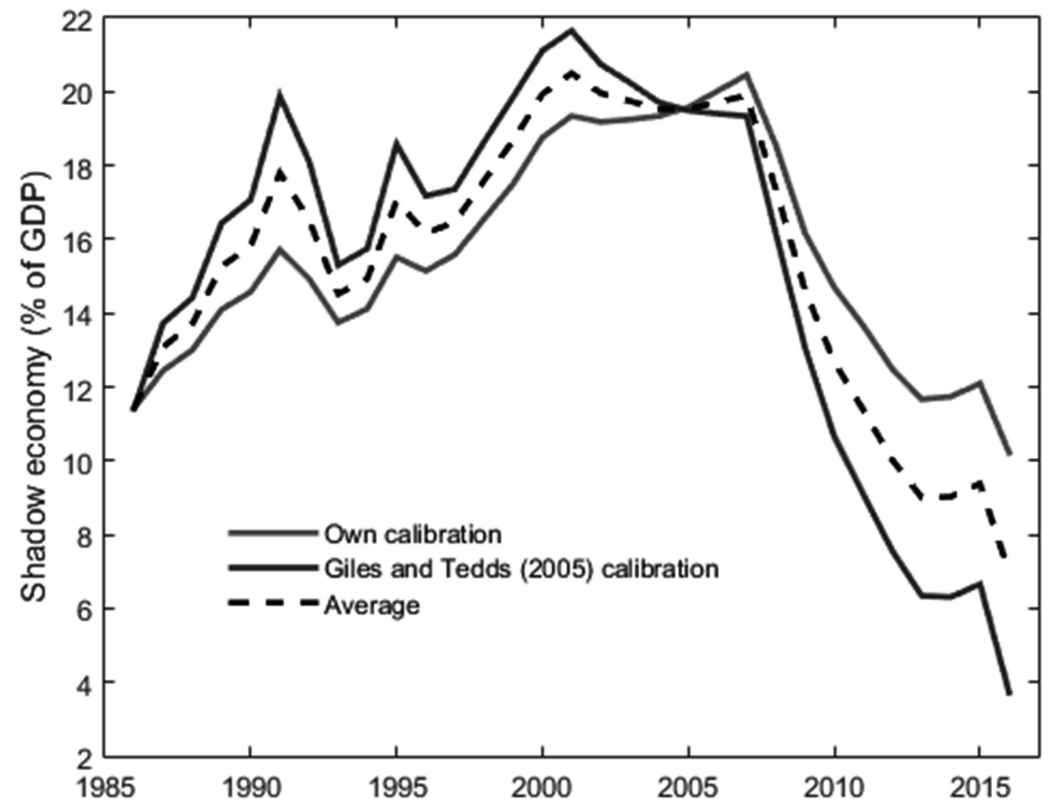


Figure 11 shows the results arising from the two calibration approaches discussed before. As can be observed, they are relatively consistent with each other, the average estimates of the shadow economy being $15.75 \%$ according to our proposed normalization and $15.33 \%$ according to Giles and Tedds' (2002). Both predict a considerable increase in the size of the shadow economy until the mid-2000s and a sharp decline following the Great Recession. The intuition behind this evolution given our coefficient estimates would be that the decline of the construction sector during the crisis dominated the effect of the increased tax burden. However, it should be noted that the drop in recent years implied by the calibration à la Giles and Tedds (2002) is very pronounced, going from a maximum of $21.6 \%$ in 2001 to $3.72 \%$ in 2016. On the other hand, the estimation derived from our first calibration proposal has a maximum value of $20.45 \%$ in 2007 and falls to $10.21 \%$ in 2016, which is more in line with the results of the CDA and the electricity consumption frameworks.

\section{The Determinants of the Shadow Economy in Navarre}

To synthetize our findings regarding the quantification exercise, Figure 12 presents the estimated dynamics of the shadow economy in Navarre obtained from the estimates implied by the different analytical approaches as well as the fit provided by a simple quadratic trend model to the arithmetic average of all of them.

Figure 12

ESTIMATION OF THE SHADOW ECONOMY IN NAVARRA, 1986-2016

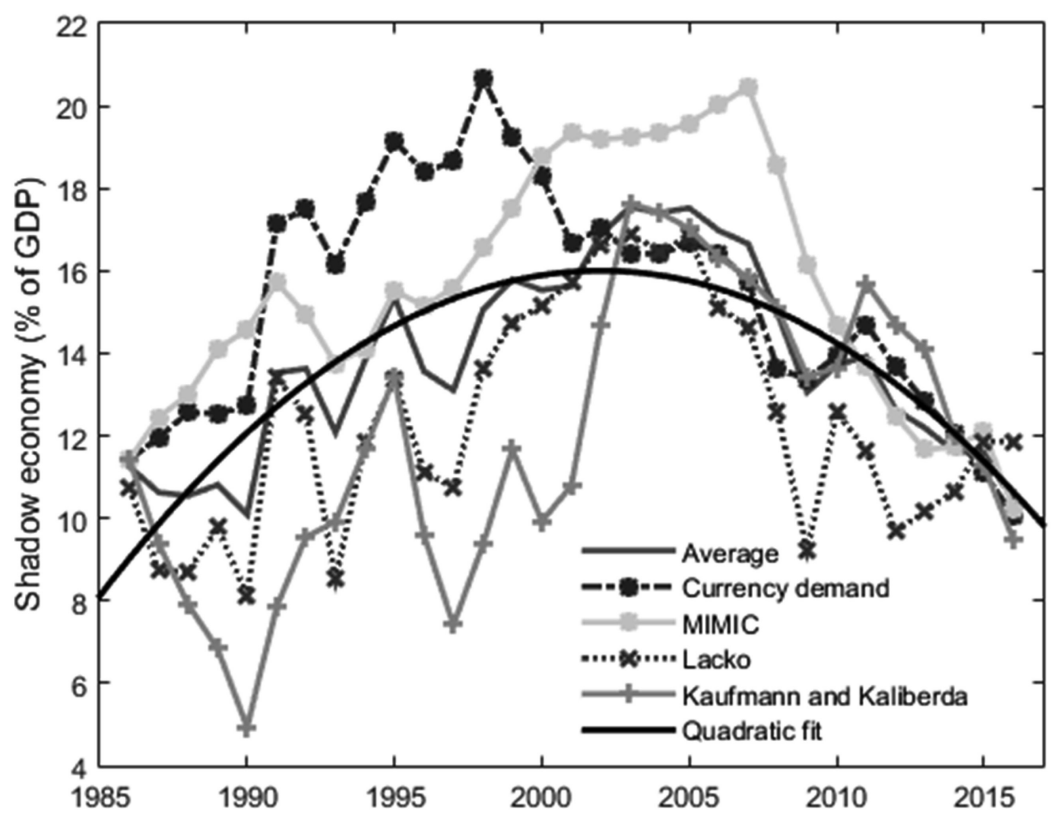


The CDA-BMA suggests an average size of the shadow economy during the study period of $15.31 \%$ of the GDP, with average fluctuations with respect to this value of about 2.8 percentage points. The results of the KK1996 electricity demand approach using TVP model estimates suggest an average size of the shadow economy of $11.94 \%$, with a value of $11.87 \%$ in 2016. On the other hand, the average size yielded by the Lackó-BMA approach is $12.38 \%$, with a final value of $9.47 \%$ in 2016. Finally, the results derived from the MIMIC method with our calibration proposals suggest that the historical average of the shadow economy is about $15.53 \%$ of the GDP.

Although there are obvious differences in the specific estimates regarding the size and the peak date, none of the maximum estimates exceeds the $22 \%$ level at any point in time. Moreover, the temporal pattern that emerges when averaging the estimates of the four methods is that of an inverted $U$, which suggests that the approaches approximate the underlying dynamics of this elusive phenomenon quite well. It is also worth mentioning that a consistent finding arising from these approaches is that during the years following the Great Recession, the shadow economy in Navarre has experienced a very pronounced decline, reaching $10.4 \%$ in 2016, the latest data available to us.

We now turn our attention to the correlates of the evolution of the shadow economy over time in Navarre. Thus, the aim is to investigate which set of factors may be responsible for the evolution depicted by our estimates of the shadow economy in Figure 12. To this end, we again employ a BMA approach to analyze the robust determinants of the shadow economy. To the best of our knowledge, this approach has never been employed before in the field of the shadow economy, although it has a long tradition in the field of macro-econometrics when it comes to investigating the robust determinants of complex processes (Moral-Benito, 2015; Steel, 2020). Thus, we now run regressions of the form:

$$
S E_{t}=X_{t} \beta+\epsilon_{t}
$$

where the dependent variable is the average size of the shadow economy (as a \% of the GDP) estimated by means of indirect approaches, while $\mathbf{X}$ stands for the matrix of potential determinants. Hence, the spirit of the following analysis is similar to that of Thieben (2010), who has investigated the role played by a large set of candidate drivers in a sample of OECD countries.

We begin by discussing the set of determinants considered in $\mathbf{X}$ and provide a brief justification for their inclusion. The first candidate determinant is the (i) tax burden, given that as we have previously discussed, it is one of the most widely accepted and important causes of the size of the underground economy. The second group of factors consists of variables that summarize the state of the economy. These are (ii) the unemployment rate, (iii) the GDP per capita growth rate, (iv) the inflation rate and (v) a dummy to capture the time effect of the Great Recession. Third, we include a variety of variables related to the industry mix, namely the share of employment in (vi) agriculture, (vii) industry, (viii) non-market services, (ix) the wholesale and retail sector and (x) construction. As we have discussed before, it is relevant to control for the fact that the share of the shadow economy varies across sectors. In addition, 
we include (xi) the ratio of cash to M1 as it increases the opportunities for leaving shadow economy transactions unreported and (xii) a dummy variable to capture the effect of Spain joining the euro area. In addition, we consider (xiii) the quality of government. Finally, we consider the role played by (xiv) the years of education and (xv) the net migration rate.

Table 2 reports the results obtained from the BMA. We scale the PIPs of the different variables classify evidence of robustness of shadow economy correlates into four categories so that regressors with PIP $<25 \%$ are considered as very weak determinants, variables with $\mathrm{PIP} \in[26-50 \%]$ as weak determinants, with PIP $\in[50-75 \%]$ as relevant and with PIP $\in$ [75$100 \%$ ] as highly important.

As can be observed, the group of very important determinants consists of the tax burden (99.5\%), the inflation rate (96.7\%) and the share of employment in the construction sector $(84.6 \%)$. These variables have a very high probability of being part of the true model underlying shadow economy outcomes, but also display a high sign of certainty above the $99 \%$ mark, which means that in most of the possible models they exert a positive impact on the size of the shadow economy. The positive effects of taxes and construction are in line with those of the MIMIC estimation and support previous empirical findings in the literature (Johnson et al., 1997, 1998; Scheneider, 2013; Schneider and Enste, 2000; Tanzi, 1999). However, in contrast to the insignificant result obtained in the MIMIC, in our BMA analysis the inflation rate appears among the top drivers of the shadow economy. This finding is in line with the insights of Feldstein (1996) and Lackó (1996, 2000), who argue that inflation may be viewed as an additional tax which rapidly increases the effective tax burden of households and firms. Thus, the downward trend of inflation which began in the 1980s may have produced a shift from an equilibrium where economic agents preferred to remain informal to avoid paying taxes and seigniorage, towards an equilibrium of higher compliance and lower inflation (Goel and Nelson, 2016).

In the group of relevant determinants, with PIPs above the 50\% threshold, we find the euro period dummy (68.8\%) and the ratio of cash outside banks to M1 (62.3\%). Both variables are positively and significantly related to the size of the underground economy at the 5\% level. The positive link between the adoption of the euro and the shadow economy may be explained by the fact that the euro strongly decreased transaction costs and increased transactions across country borders, but as a by-product, it fostered so-called VAT carousel fraud, because under European Union rules, tradable services are highly vulnerable to both missing trader intra-community fraud and missing trader extra-community fraud (OECD, 2017). An alternative explanation is that after entering the euro area, the shift towards banknotes of a higher denomination than those existing at the time of the peseta made it easier to store the value created in shadow economic activities, thereby providing incentives to operate in the underground economy.

On the other hand, the positive effect of the amount of currency relative to M1 can be explained by the fact that cash payments can promote activity in the underground economy, as they provide an incentive not to report transactions and avoid paying taxes (Dybka et al., 2019; Tanzi, 1983). 
Table 2

THE DRIVERS OF THE SHADOW ECONOMY. BAYESIAN MODEL AVERAGING RESULTS

\begin{tabular}{|c|c|c|c|c|}
\hline Variables & $\begin{array}{c}\text { PIPs } \\
\text { (1) }\end{array}$ & $\begin{array}{c}\text { Unstandardized } \\
\text { Posterior Estimates } \\
\text { (2) }\end{array}$ & $\begin{array}{c}\text { Standardized } \\
\text { Posterior Estimates } \\
\text { (3) }\end{array}$ & $\begin{array}{c}\text { Posterior Sign } \\
\text { Positivity } \\
\text { (4) }\end{array}$ \\
\hline $\begin{array}{l}\text { Tax burden (inc. Soc. } \\
\text { Contrib.) }\end{array}$ & 0.995 & $\begin{array}{l}0.413^{* * *} \\
(0.102)\end{array}$ & $\begin{array}{l}0.780^{* * *} \\
(0.193)\end{array}$ & 1.000 \\
\hline Inflation rate & 0.967 & $\begin{array}{l}0.307^{* * *} \\
(0,080)\end{array}$ & $\begin{array}{l}0.384^{* * * *} \\
(0,100)\end{array}$ & 1.000 \\
\hline Emp. Construction & 0.846 & $\begin{array}{l}0.432^{* * * *} \\
(0.145)\end{array}$ & $\begin{array}{l}0.442^{* * * *} \\
(0,148\end{array}$ & 1,000 \\
\hline Euro & 0.688 & $\begin{array}{l}0,020^{* * * *} \\
(0,007)\end{array}$ & $\begin{array}{l}0.434^{* * *} \\
(0,159)\end{array}$ & 1,000 \\
\hline Cash outside banks/M1 & 0.623 & $\begin{array}{c}0.060^{* *} \\
(0.024)\end{array}$ & $\begin{array}{c}0.459^{* *} \\
(0.180)\end{array}$ & 0,998 \\
\hline Emp. Non-market services & 0.228 & $\begin{array}{l}-0.320^{*} \\
(0.173)\end{array}$ & $\begin{array}{l}-0.431^{*} \\
(0.233)\end{array}$ & 0.002 \\
\hline Unemployment & 0.153 & $\begin{array}{c}0.115 \\
(0.119)\end{array}$ & $\begin{array}{c}0.179 \\
(0.186)\end{array}$ & 0.914 \\
\hline Crisis & 0.125 & $\begin{array}{c}0.005 \\
(0.005)\end{array}$ & $\begin{array}{c}0.089 \\
(0.084)\end{array}$ & 0.987 \\
\hline Emp. Retail & 0.119 & $\begin{array}{l}-0.207 \\
(0.308)\end{array}$ & $\begin{array}{l}-0.106 \\
(0.158)\end{array}$ & 0.214 \\
\hline Emp. Industry & 0.109 & $\begin{array}{l}-0.189 \\
(0.331)\end{array}$ & $\begin{array}{l}-0.295 \\
(0.516)\end{array}$ & 0.178 \\
\hline Education & 0.104 & $\begin{array}{l}-0.002 \\
(0.011)\end{array}$ & $\begin{array}{l}-0.096 \\
(0.562)\end{array}$ & 0.417 \\
\hline Net migration rate & 0.103 & $\begin{array}{l}-0.002 \\
(0.002)\end{array}$ & $\begin{array}{l}-0.064 \\
(0.073)\end{array}$ & 0.016 \\
\hline Real GDP growth & 0.093 & $\begin{array}{c}0.040 \\
(0.070)\end{array}$ & $\begin{array}{c}0.077 \\
(0.133)\end{array}$ & 0.821 \\
\hline Emp. agriculture & 0.087 & $\begin{array}{l}-0.007 \\
(0.202)\end{array}$ & $\begin{array}{l}-0.005 \\
(0.136)\end{array}$ & 0.573 \\
\hline Self employment & 0.082 & $\begin{array}{l}-0.078 \\
(0.149)\end{array}$ & $\begin{array}{l}-0.056 \\
(0.106)\end{array}$ & 0.071 \\
\hline Quality of government & 0.072 & $\begin{array}{c}0.002 \\
(0.012)\end{array}$ & $\begin{array}{c}0.018 \\
(0.106)\end{array}$ & 0.748 \\
\hline
\end{tabular}

Notes: The dependent variable in all regressions is the average shadow economy (\% of GDP) index obtained from indirect macroeconomic approaches. The results reported here correspond to the estimation of the top 1,000 models from the 65.5 thousand possible regressions including any combination of the 16 variables. Prior mean model size is 8 . Variables are ranked by Column (1), the posterior inclusion probability. Columns (2) to (3) reflect the unstandardized and standardized posterior mean and standard deviations for the linear marginal effect of the variable conditional on inclusion in the model, respectively. Column (4) denotes the sign certainty probability, a measure of our posterior confidence in the sign of the coefficient. ${ }^{*}$ Significant at $10 \%$ level, ${ }^{* *}$ significant at $5 \%$ level, ${ }^{* * *}$ significant at $1 \%$ level. 
In addition, we find a weakly significant negative effect of the share of non-market services, although with a PIP $<50 \%$. The reason for this result is that most people in non-market services are employed in the public sector, which reduces the possibility of under-reporting income relative to other jobs. Importantly, none of the remaining factors considered appear to be relevant in explaining the regional evolution of the shadow economy over time from either a Bayesian or a frequentist perspective, as they display PIPs below the a priori posterior probability of $50 \%$ and are not significant at conventional levels.

Finally, in Table (A7) and Figure (A4) we provide further checks that show the robustness of these findings with respect to the choice of priors on the model size and the parameters.

\section{Conclusions}

This study has investigated the evolution of the shadow economy in the Spanish region of Navarre during the period 1986-2016 using the Currency Demand approach, Electricity Consumption (Physical Input) methods -including its two variants, the KK1996 approach and the Lackó (2000) approach- and the MIMIC method.

In this exercise, we have introduced methodological innovations such as the BMA to obtain parameter estimates and account for model uncertainty in the specification of tax indicators and the use of parameter models and novel calibration proposals. The aim of introducing these procedures, which are becoming increasingly widespread in the field of macro-econometrics, has been to refine the measurements of the shadow economy and to partially solve some of the problems present in the indirect methods commonly employed in the literature.

The main finding of this empirical analysis is that the evolution of the shadow economy has displayed a clear U-shaped profile over time; indeed, all the econometrically improved methods applied in this research reproduce this profile. Our final estimate suggests an average size of the shadow economy for the period under analysis of $13.8 \%$, including $10.4 \%$ at the end of the period in 2016. These figures are lower than the Spanish national average but close to those of the Basque Country. We conjecture that the causes of this difference are Navarre's unique capacity to develop tax control plans at the regional level (due to the region's special status) and the contrasting sectoral structure of the economy.

In a second step, after quantifying the shadow economy, we analyzed its determinants. We have found that the evolution of the shadow economy in Navarre can be explained by a small and robust set of robust factors: the tax burden, the share of employment in the construction sector, inflation, Spain's adoption of the euro and the ratio of currency to M1. These factors should be considered for their policy implications. For example, the prominent positive link between employment in the construction sector and the size of the shadow economy calls for closer surveillance on this sector. Moreover, the positive relationship between the size of the hidden sector and the ratio of currency to M1 suggests that it would be advisable to reduce the volume of cash-based transactions, for example, by fixing a low ceiling in legal 
economic transactions using cash and encouraging the use of electronic payments through the financial sector, which can be traced by the Treasury. Given that the tax burden has proved to be the main determinant of the size of the shadow economy, the public administration should increase the perceived quality of public services in order to incentivize tax compliance. 


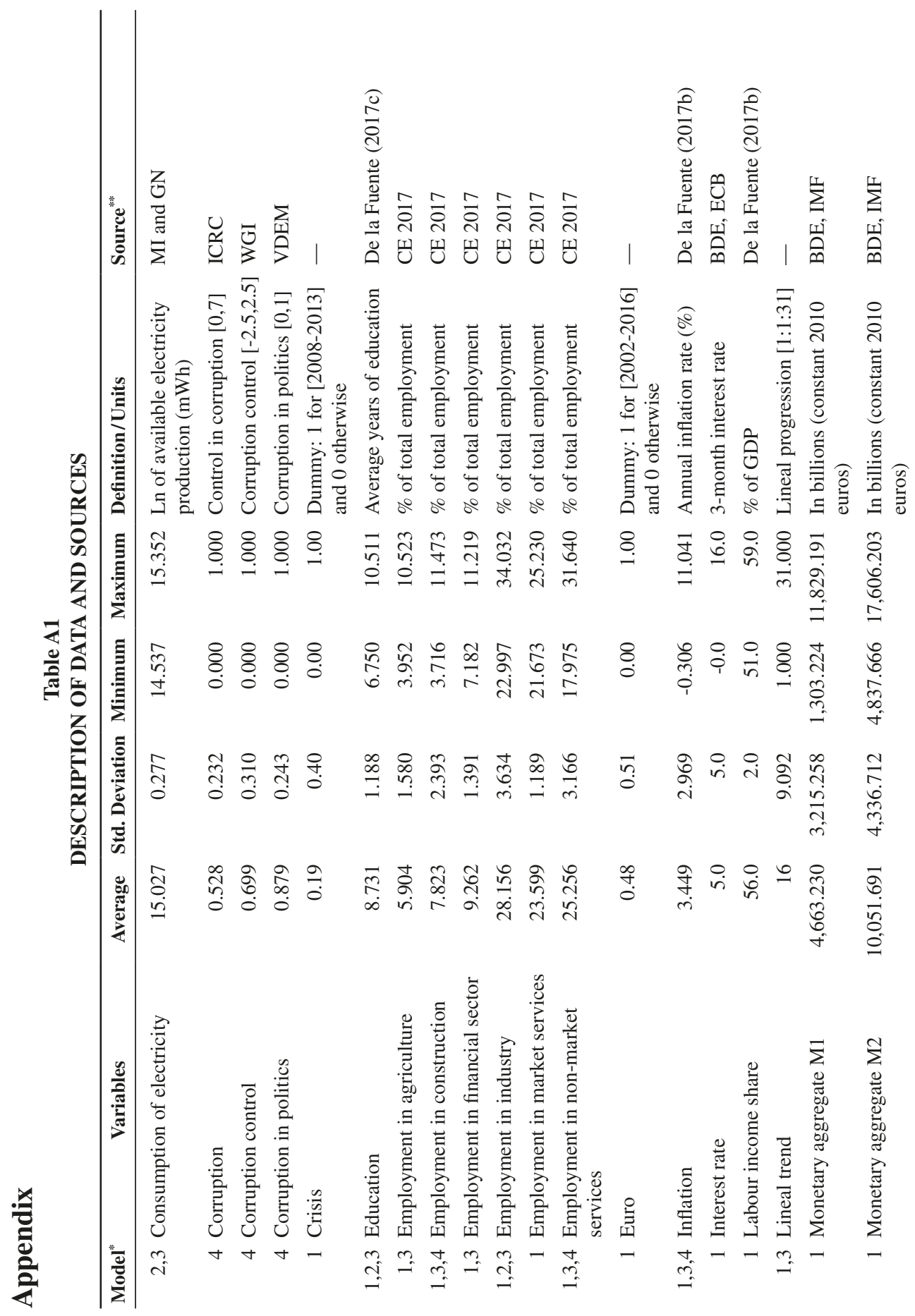




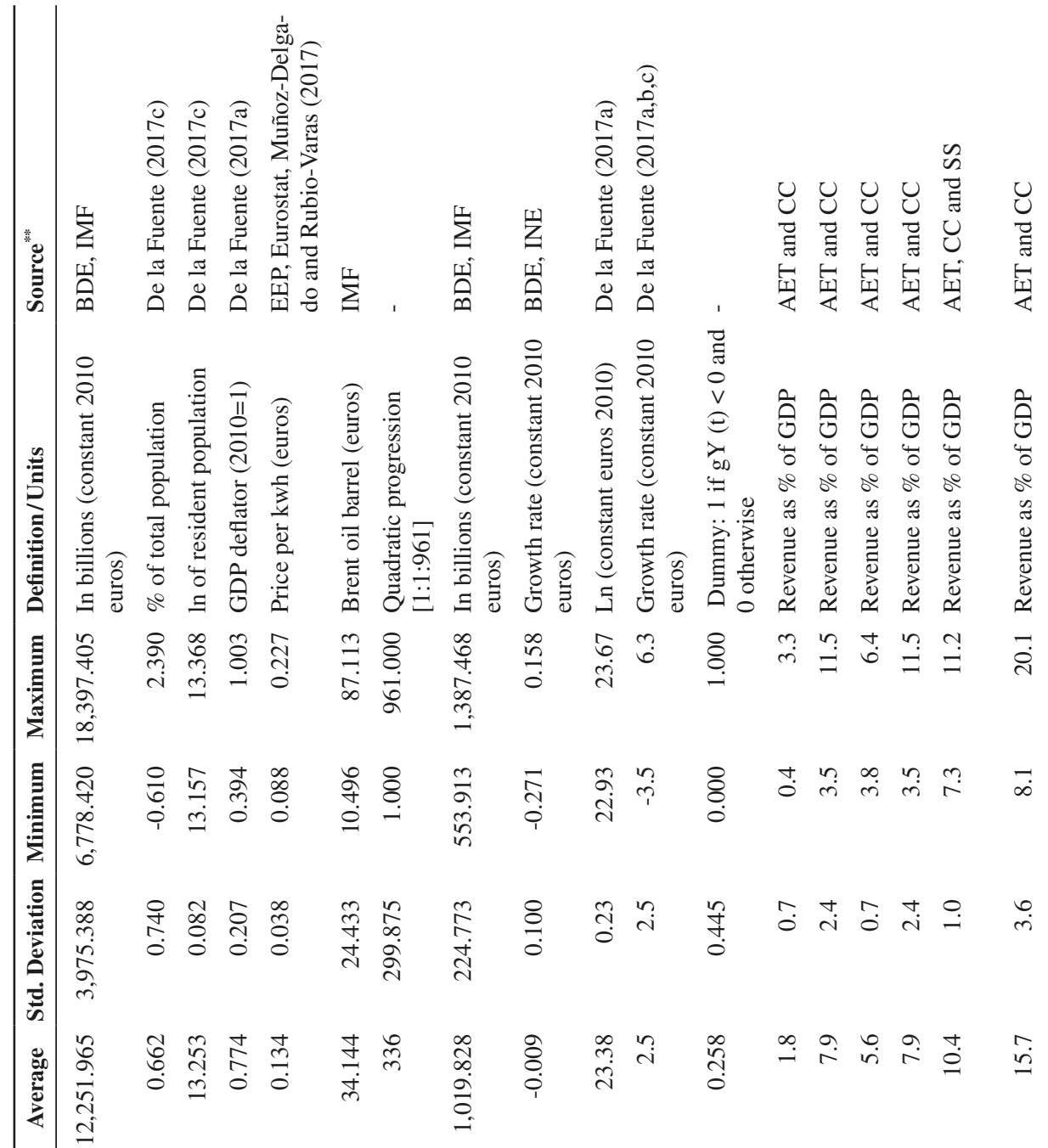

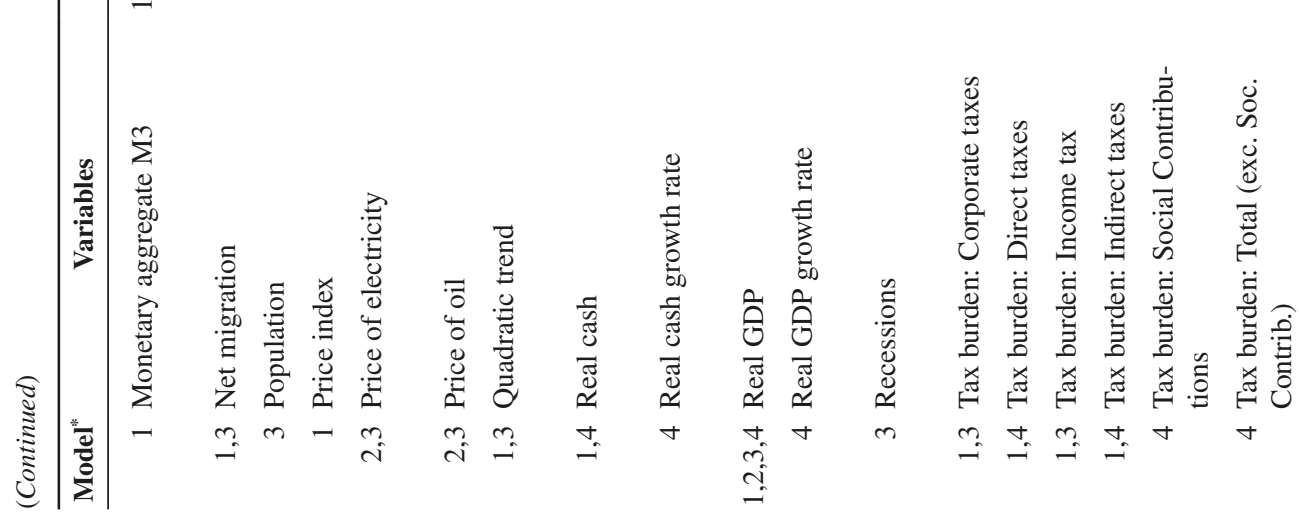




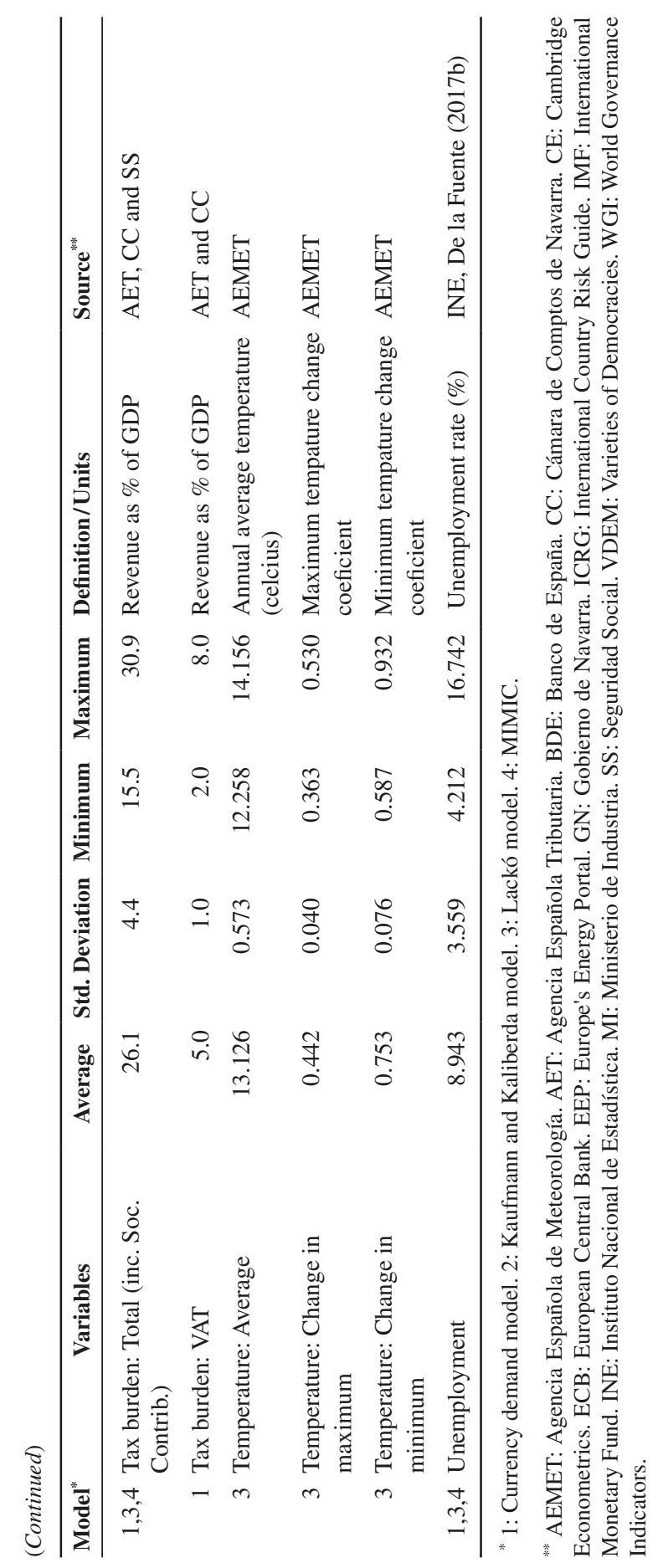


Table A2

CURRENCY DEMAND MODELS: RESULTS WITH BMA

\begin{tabular}{|c|c|c|c|c|c|}
\hline Variable & $\begin{array}{c}\text { PIP } \\
(1) \\
\end{array}$ & $\begin{array}{c}\text { Cond. Mean } \\
\text { Post. (PM) } \\
(2) \\
\end{array}$ & $\begin{array}{c}\text { Cond. Stand. } \\
\text { Dev. (PSD } \\
\text { (3) } \\
\end{array}$ & $\begin{array}{c}\text { t-Stat }>1.96 \\
(4)\end{array}$ & $\begin{array}{c}\text { Posterior. } \\
\text { Sign. Pos } \\
\text { (5) }\end{array}$ \\
\hline Total tax burden (inc. Soc. Contrib.) & 1.000 & 2.763 & 1.517 & 0.547 & 1.000 \\
\hline Unemployment & 1.000 & 5.271 & 2.025 & 0.952 & 1.000 \\
\hline Real GDP & 1.000 & 2.547 & 1.116 & 0.892 & 1.000 \\
\hline Inflation & 1.000 & 0.543 & 1.332 & 0.058 & 0.688 \\
\hline Interest rate & 1.000 & 0.621 & 1.834 & 0.034 & 0.745 \\
\hline Quadratic trend & 1.000 & -0.003 & 0.001 & 1.000 & 0.000 \\
\hline Euro & 1.000 & -0.101 & 0.095 & 0.012 & 0.024 \\
\hline Employment in non-market services & 0.992 & -3.589 & 2.887 & 0.500 & 0.216 \\
\hline Lineal trend & 0.982 & 0.061 & 0.106 & 0.567 & 0.700 \\
\hline Education & 0.893 & -0.271 & 0.564 & 0.181 & 0.356 \\
\hline Labour income share & 0.786 & 0.329 & 2.106 & 0.146 & 0.427 \\
\hline Employment in agriculture & 0.745 & -7.139 & 4.266 & 0.758 & 0.018 \\
\hline Employment in financial sector & 0.651 & 2.120 & 2.996 & 0.344 & 0.740 \\
\hline Crisis & 0.545 & -0.025 & 0.066 & 0.000 & 0.195 \\
\hline Employment in construction & 0.391 & 1.591 & 2.848 & 0.086 & 0.681 \\
\hline Employment in market services & 0.325 & 3.840 & 1.996 & 0.674 & 0.925 \\
\hline Net migration & 0.324 & -0.002 & 0.017 & 0.000 & 0.367 \\
\hline Employment in industry & 0.150 & -0.232 & 1.502 & 0.016 & 0.445 \\
\hline
\end{tabular}

Notes: The dependent variable is the log of real currency Results correspond to the estimation of 757 models out of 1276 models which satisfy restrictions. The variables are ordered according to the probability of being included in the model (PIP). Column (1) displays the posterior inclusion probability. Columns (2) to (3) the posterior mean, standard deviations for the linear marginal effect of the variable conditional on inclusion in the model, respectively. Column (4) is the fraction of regressions in which the coefficient has a classical t-test greater than 1.96, with all regressions having equal sampling probability. The last column denotes the sign certainty probability, a measure of our posterior confidence in the sign of the coefficient. 


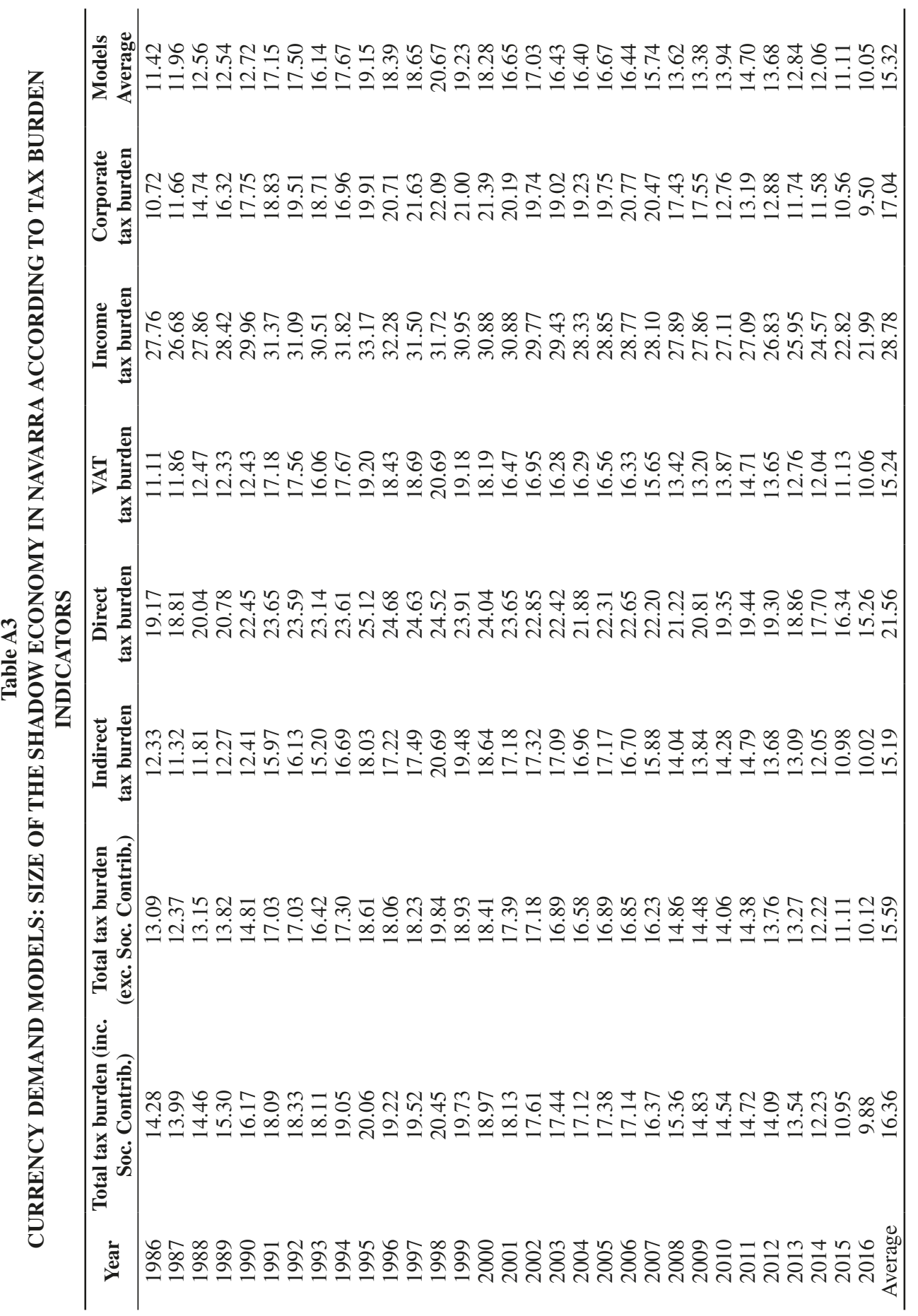




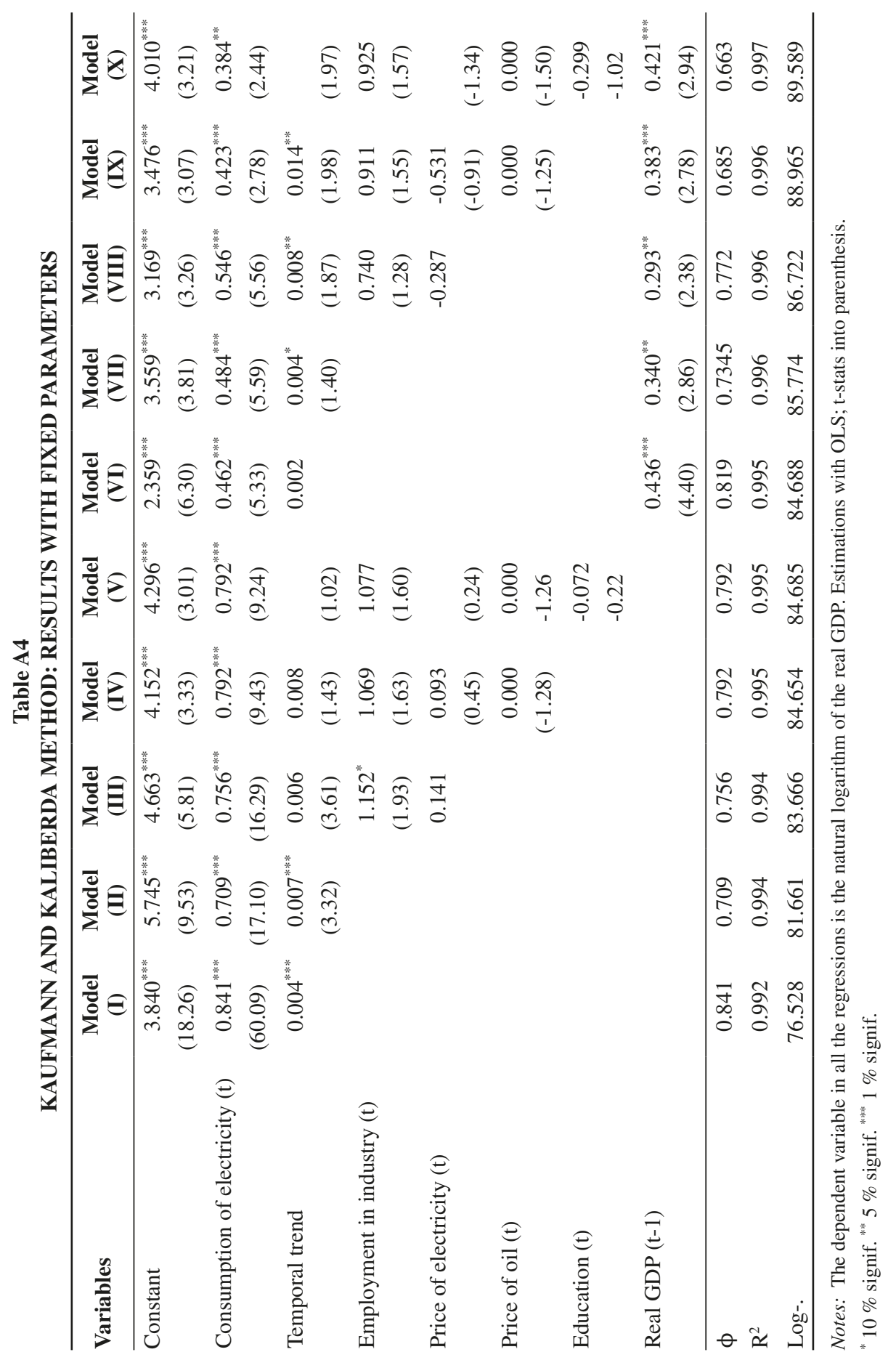


Table A5

KAUFMANN AND KALIBERDA METHOD: RESULTS WITH TVP ESTIMATIONS

\begin{tabular}{|c|c|c|c|c|c|c|c|c|}
\hline & $\begin{array}{l}\text { Model } \\
\text { (I) }\end{array}$ & $\begin{array}{l}\text { Model } \\
\text { (II) }\end{array}$ & $\begin{array}{c}\text { Model } \\
\text { (III) }\end{array}$ & $\begin{array}{c}\text { Model } \\
\text { (IV) }\end{array}$ & $\begin{array}{c}\text { Model } \\
\text { (V) }\end{array}$ & $\begin{array}{c}\text { Model } \\
\text { (VI) }\end{array}$ & $\begin{array}{c}\text { Model } \\
\text { (VII) }\end{array}$ & $\begin{array}{l}\text { Model } \\
\text { (VIII) }\end{array}$ \\
\hline \multicolumn{9}{|l|}{$\lambda=\mathbf{0 . 9 0}$} \\
\hline Constant & 0.005 & 0.005 & 0.005 & 0.005 & 0.0018 & 0.0019 & 0.0019 & 0.002 \\
\hline Consumption of electricity $(\mathrm{t})$ & 0.967 & 0.949 & 0.945 & 0.878 & 0.3954 & 0.3922 & 0.3906 & 0.3752 \\
\hline Employment in industry (t) & & 0.871 & 0.935 & 1.137 & & 0.1449 & 0.1747 & 0.3085 \\
\hline Price of electricity $(t)$ & & & 0.339 & 0.252 & & & 0.0616 & 0.0267 \\
\hline Price of oil (t) & & & 0.000 & 0.000 & & & 0.0002 & 0.0002 \\
\hline Education $(\mathrm{t})$ & & & & 0.460 & & & & 0.2214 \\
\hline Real GDP (t-1) & & & & & 0.5225 & 0.5221 & 0.5222 & 0.5063 \\
\hline RMSE & 2.5634 & 2.5636 & 2.5635 & 2.5633 & 2.5634 & 2.5635 & 2.5635 & 2.5634 \\
\hline MAE & 0.4702 & 0.4874 & 0.4847 & 0.4662 & 0.4767 & 0.4797 & 0.4805 & 0.4737 \\
\hline \multicolumn{9}{|l|}{$\lambda=0.95$} \\
\hline Constant & 0.0054 & 0.0051 & 0.0051 & 0.0049 & 0.002 & 0.002 & 0.002 & 0.002 \\
\hline Consumption of electricity $(\mathrm{t})$ & 0.9669 & 0.9466 & 0.9423 & 0.8774 & 0.3894 & 0.3869 & 0.3859 & 0.3718 \\
\hline Employment in industry (t) & & 0.9572 & 1.01 & 1.1567 & & 0.2242 & 0.2552 & 0.3556 \\
\hline Price of electricity $(\mathrm{t})$ & & & 0.3719 & 0.2826 & & & 0.1245 & 0.0882 \\
\hline Price of oil (t) & & & 0.0003 & 0.0002 & & & 0.0002 & 0.0002 \\
\hline Education $(\mathrm{t})$ & & & & 0.4601 & & & & 0.2153 \\
\hline Real GDP (t-1) & & & & & 0.5276 & 0.5251 & 0.5244 & 0.5088 \\
\hline RMSE & 2.5634 & 2.5637 & 2.5637 & 2.5637 & 2.5633 & 2.5636 & 2.5636 & 2.5634 \\
\hline MAE & 0.4749 & 0.499 & 0.499 & 0.4926 & 0.4688 & 0.4855 & 0.4853 & 0.4768 \\
\hline \multicolumn{9}{|l|}{$\lambda=0.99$} \\
\hline Constant & 0.005 & 0.005 & 0.005 & 0.005 & 0.0018 & 0.0019 & 0.0019 & 0.002 \\
\hline Consumption of electricity $(\mathrm{t})$ & 0.967 & 0.949 & 0.945 & 0.878 & 0.3954 & 0.3922 & 0.3906 & 0.3752 \\
\hline Employment in industry (t) & & 0.871 & 0.935 & 1.137 & & 0.1449 & 0.1747 & 0.3085 \\
\hline Price of electricity $(t)$ & & & 0.339 & 0.252 & & & 0.0616 & 0.0267 \\
\hline Price of oil (t) & & & 0.000 & 0.000 & & & 0.0002 & 0.0002 \\
\hline Education (t) & & & & 0.460 & & & & 0.2214 \\
\hline Real GDP (t-1) & & & & & 0.5225 & 0.5221 & 0.5222 & 0.5063 \\
\hline RMSE & 2.5634 & 2.5636 & 2.5635 & 2.5633 & 2.5634 & 2.5635 & 2.5635 & 2.5634 \\
\hline MAE & 0.4702 & 0.4874 & 0.4847 & 0.4662 & 0.4767 & 0.4797 & 0.4805 & 0.4737 \\
\hline
\end{tabular}

Note: The dependent variable in all the regressions is the natural logarithm of the real GDP. Parameter estimations are their temporal average. 
Table A6

LACKÓ METHOD: RESULTS WITH BMA

\begin{tabular}{|c|c|c|c|c|c|}
\hline Variable & $\begin{array}{c}\text { PIP } \\
(\mathbf{1})\end{array}$ & $\begin{array}{c}\text { Cond. Average } \\
\text { Post. (PM) } \\
\text { (2) }\end{array}$ & $\begin{array}{c}\text { Cond. Stand. } \\
\text { Dev. (PSD) } \\
(3) \\
\end{array}$ & $\begin{array}{c}\text { t-Stat } \\
>1.96 \\
(4) \\
\end{array}$ & $\begin{array}{c}\text { Posit. } \\
\text { sign } \\
(5) \\
\end{array}$ \\
\hline Total tax burden (inc. Soc. Contrib.) & 1.000 & 0.0074 & 0.0091 & 0.00 & 1.00 \\
\hline Income tax burden & 1.000 & 0.8330 & 0.2662 & 0.97 & 1.00 \\
\hline Corporate tax burden & 1.000 & -0.9711 & 0.4845 & 0.79 & 0.00 \\
\hline Unemployment & 1.000 & 0.7113 & 0.5954 & 0.26 & 1.00 \\
\hline Inflation & 1.000 & 0.2592 & 0.5154 & 0.09 & 1.00 \\
\hline Recessions & 1.000 & -0.919 & 15.671 & 0.06 & 0.09 \\
\hline Real GDP & 0.999 & 0.0012 & 0.5273 & 0.50 & 0.54 \\
\hline Employment in industry & 0.751 & -0.3244 & 0.8742 & 0.00 & 0.25 \\
\hline Price of electricity & 0.623 & 0.4387 & 0.2498 & 0.88 & 1.00 \\
\hline Education & 0.551 & -0.0279 & 0.0335 & 0.00 & 0.00 \\
\hline Employment in construction & 0.237 & -0.1619 & 0.5083 & 0.00 & 0.31 \\
\hline Lineal temporal trend & 0.207 & -0.0007 & 0.0028 & 0.00 & 0.17 \\
\hline Population & 0.180 & 0.0044 & 0.0047 & 0.13 & 0.95 \\
\hline Employment in financial sector & 0.172 & 10.809 & 0.4911 & 0.83 & 1.00 \\
\hline Change minimum temperature & 0.105 & 0.0371 & 0.0234 & 0.00 & 1.00 \\
\hline Net migration & 0.084 & 0.0074 & 0.0035 & 0.00 & 1.00 \\
\hline Change maximum temperature & 0.046 & 0.1382 & 0.0314 & 0.00 & 1.00 \\
\hline Employment in non-market services & 0.003 & 0.3541 & 0.0485 & 0.00 & 0.88 \\
\hline Employment in agriculture & 0.003 & -0.7468 & 0.0643 & 0.00 & 0.00 \\
\hline Price of oil & 0.000 & 0.0002 & 0.0000 & 0.00 & 0.80 \\
\hline Average temperature & 0.000 & -23.187 & 0.0345 & 0.20 & 0.00 \\
\hline Quadratic temporal trend & 0.000 & 0.0000 & 0.0000 & 0.00 & 1.00 \\
\hline
\end{tabular}

Notes: The dependent variable is the natural logarithm of the electrical consumption. Results correspond to the estimation of 131 models out of 599 which satisfy conditions. The variables are ordered according to the probability of being included in the model (PIP). Column (1) displays the posterior inclusion probability. Columns (2) to (3) the posterior mean, standard deviations for the linear marginal effect of the variable conditional on inclusion in the model, respectively. Column (4) is the fraction of regressions in which the coefficient has a classical t-test greater than 1.96, with all regressions having equal sampling probability. The last column denotes the sign certainty probability, a measure of our posterior confidence in the sign of the coefficient. 
Table A7

POSTERIOR INCLUSION PROBABILITIES FOR DIFFERENT MODEL SIZE PRIORS

\begin{tabular}{lcccc}
\hline & $\begin{array}{c}\text { Prior model } \\
\text { size, } \mathbf{k = 6}\end{array}$ & $\begin{array}{c}\text { Prior model } \\
\text { size, k=8 }\end{array}$ & $\begin{array}{c}\text { Prior model } \\
\text { size, k=10 }\end{array}$ & $\begin{array}{c}\text { Prior model } \\
\text { size, k=12 }\end{array}$ \\
\hline Tax burden (inc. Soc. Contrib) & $0,992^{*}$ & $0,995^{*}$ & $0,996^{*}$ & $0,998^{*}$ \\
Inflation rate & $0,944^{*}$ & $0,967^{*}$ & $0,977^{*}$ & $0,989^{*}$ \\
Emp. Construction & $0,868^{*}$ & $0,846^{*}$ & $0,810^{*}$ & $0,931^{*}$ \\
Euro & $0,426^{*}$ & $0,688^{*}$ & $0,815^{*}$ & $0,906^{*}$ \\
Cash outside banks/M1 & $0,384^{*}$ & $0,623^{*}$ & $0,763^{*}$ & 0,685 \\
Emp. Non-market services & 0,170 & 0,228 & 0,296 & 0,482 \\
Unemployment & 0,111 & 0,153 & 0,182 & 0,238 \\
Crisis & 0,061 & 0,125 & 0,198 & 0,383 \\
Emp. Retail & 0,053 & 0,119 & 0,203 & 0,434 \\
Emp. Industry & 0,053 & 0,109 & 0,181 & 0,389 \\
Education & 0,064 & 0,104 & 0,138 & 0,215 \\
Net migration & 0,053 & 0,103 & 0,149 & 0,241 \\
Real GDP growth & 0,045 & 0,093 & 0,147 & 0,293 \\
Emp. Agriculture & 0,047 & 0,087 & 0,125 & 0,213 \\
Self-employment & 0,047 & 0,082 & 0,117 & 0,204 \\
Quality of government & 0,040 & 0,072 & 0,102 & 0,174 \\
\hline
\end{tabular}

Notes: The dependent variable in all regressions is the average shadow economy (\% of GDP) index obtained from the various indirect macroeconomic approaches. The results reported here correspond to the estimation of the top 1,000 models from the 65.5 thousand possible regressions including any combination of the 16 variables. Each column reflects a different Binomial prior on the model size. To assess variable the robustness of our variable importance analysis we compare the posterior inclusion probabilities (PIPs) with the a priori posterior model probability (APIPs). ${ }^{*}$ denotes PIPS > APIPS. 
Figure A1

CURRENCY IN CIRCULATION

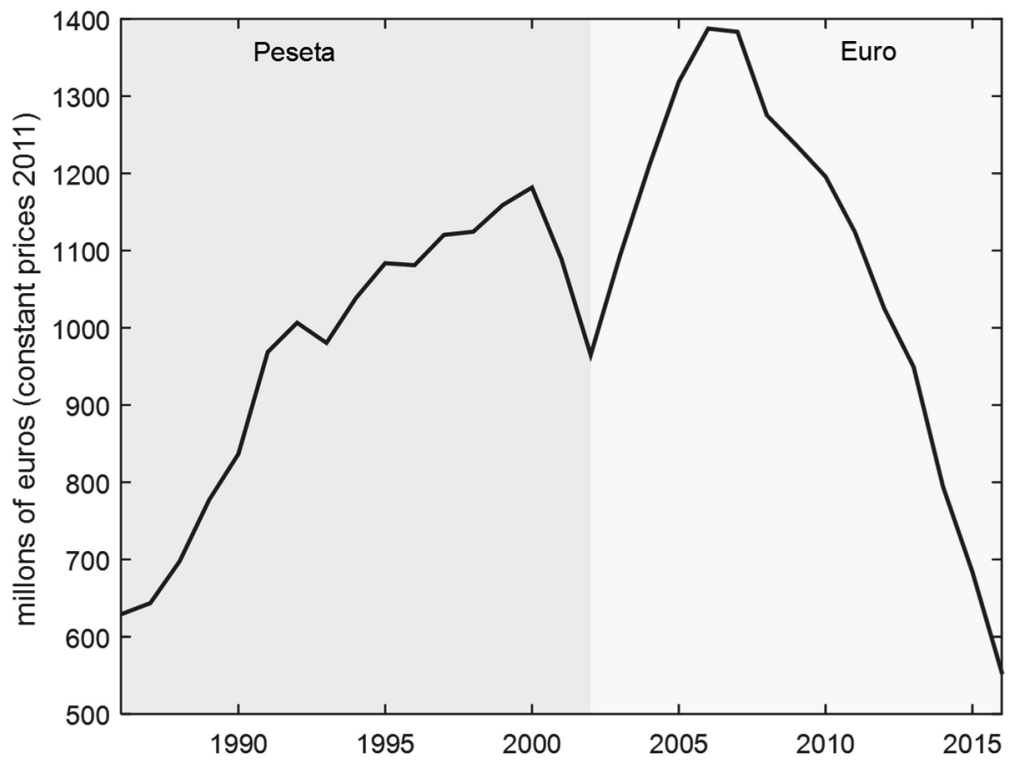

Figure A2

BAYESIAN MODEL AVERAGED CDA AND FREQUENTIST-CDA ESTIMATES ${ }^{19}$

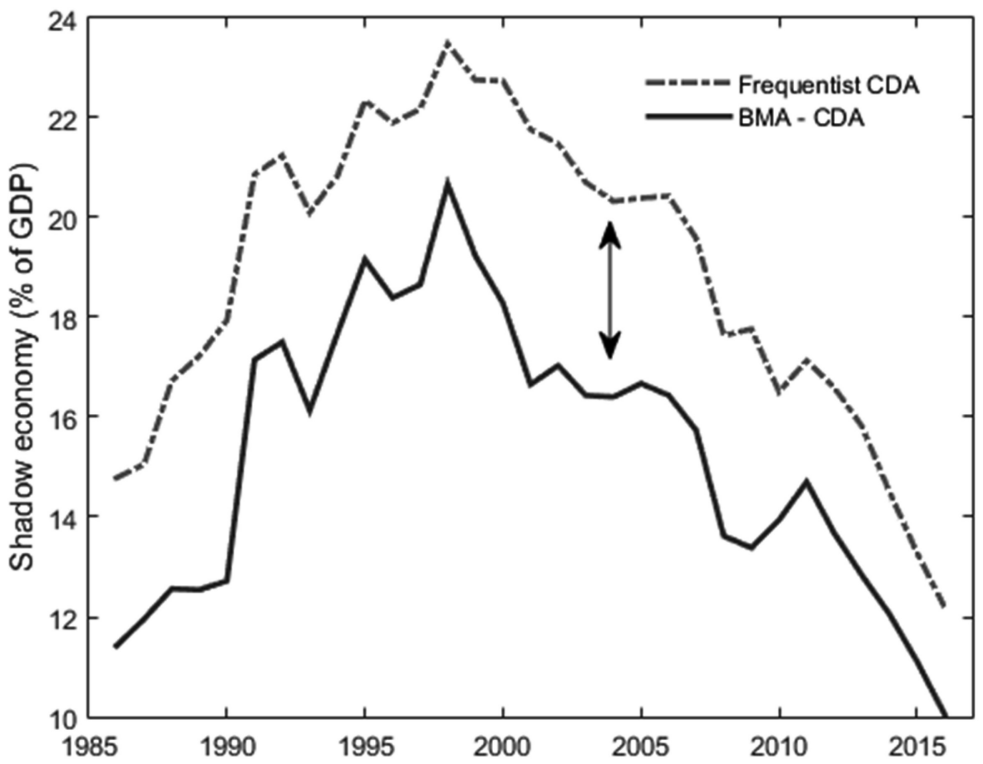


Figure A3

\section{ESTIMATED ELASTICITIES $\widehat{\phi_{t}}$ WITH TVP MODELS}

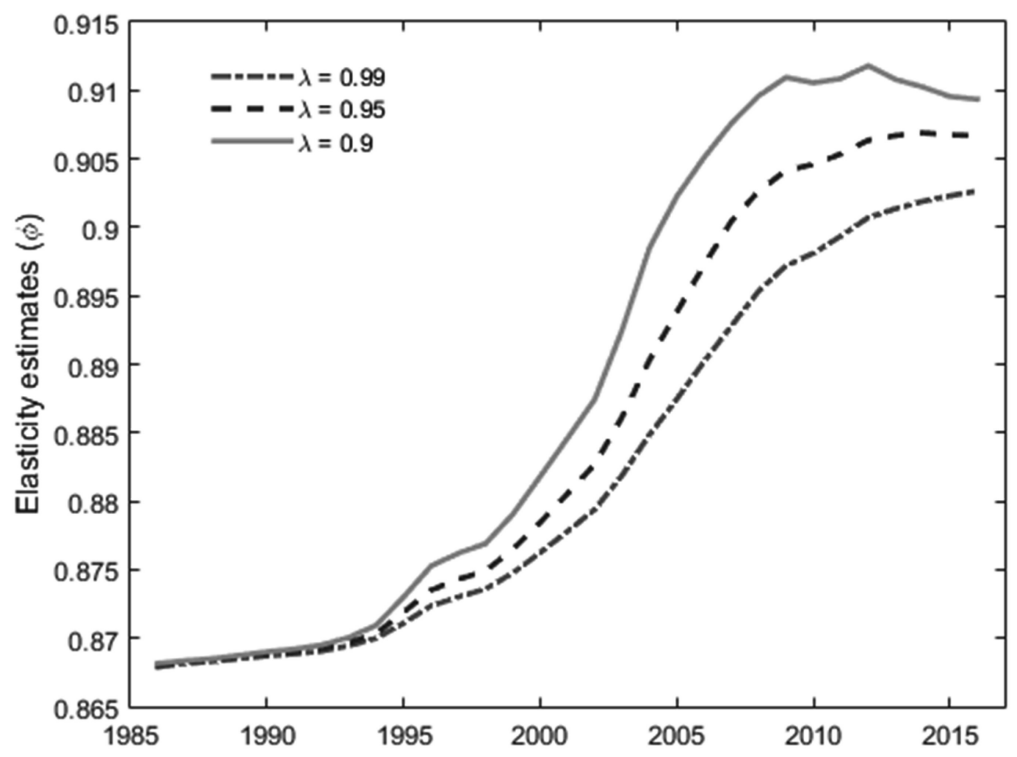

Figure A4

ALTERNATIVE G-PRIOR SPECIFICATIONS

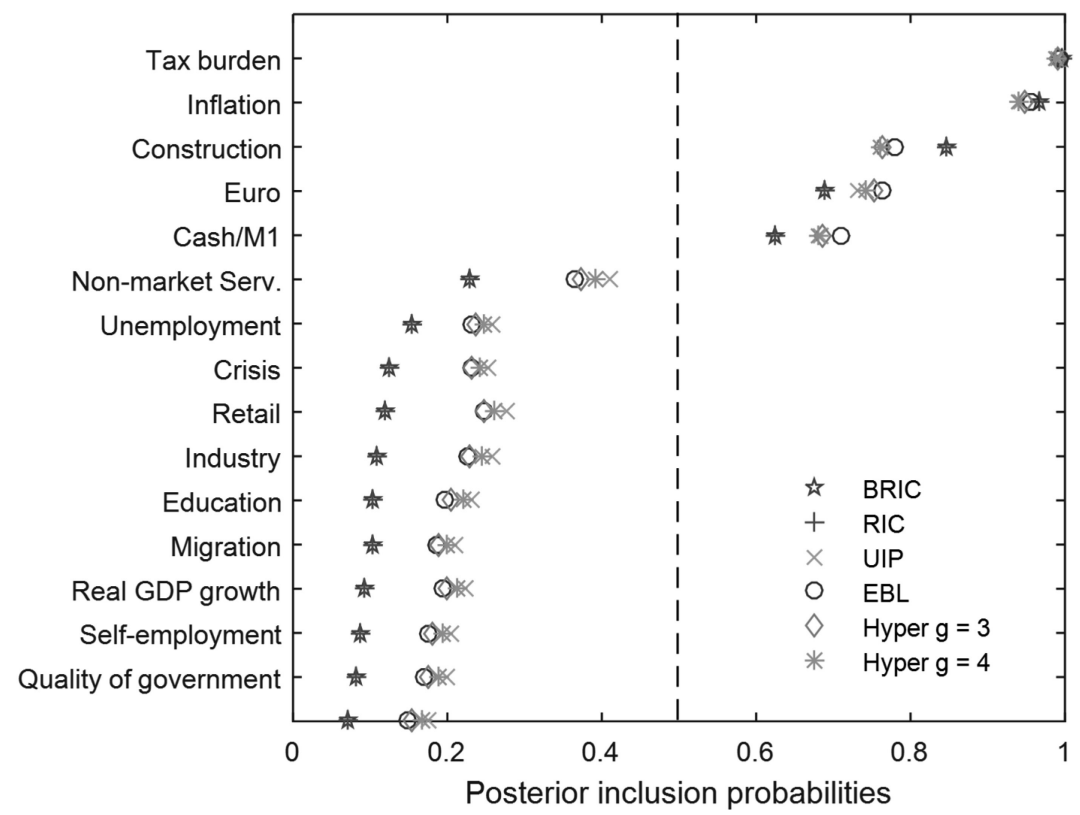

Note: For more details on alternative g-prior specifications see Zeugner and Feldkircher (2015). 


\section{Notes}

1. Traditionally the shadow economy has been defined as all unregistered economic activities that would contribute to the officially calculated (or observed) gross national product if observed. However, since the 2014 Eurostat methodological review, some illegal activities such as prostitution, drug sales, tobacco smuggling and illegal gambling have been included in the National Accounts of Spain, in accordance with a new standard approved in the European Union, the so-called European System of National and Regional Accounts 2010 (ESA, 2010).

2. The economic contribution must be calculated and agreed upon every five years. In the five-year period 20152019, the final contribution for the base year 2015 was $€ 510$ million, which represented $15.5 \%$ of current revenues (15.7\% of tax revenues) and $13 \%$ of total expenditure. In 2019, the last year of the five-year period, Navarre's economic contribution was $€ 547.7$ million, that is, $13.1 \%$ of current revenues (13.9\% of tax revenues) and $12.4 \%$ of total expenditure.

3. The Economic Complexity Index (ECI) measures the knowledge in a society expressed in the products it makes. The economic complexity of a country is calculated based on the diversity of exports it produces and their ubiquity, or the number of countries able to produce them (and those countries' complexity). Thus, the high ECI in Navarre means it exports many sophisticated goods that are of low ubiquity (i.e. few other regions can make them).

4. In particular, our g-prior hyper-parameter takes the value of $g_{k}=1 / \max \left\{n, K^{2}\right\}$ such that $g\left(\eta_{k}\right) \sim$ $N\left[0, \sigma^{2}\left(g_{k} X_{k}^{\prime} X_{k}\right)^{-1}\right]$. We also set a binomial prior on the model to regulate prior model probabilities. according to $p\left(M_{k}\right)=\phi^{k}(1-\phi)^{K-k}$, where each covariate $k$ is included in the model with a probability of success $\phi$. We set $\phi=1 / 2$ to assign equal probability $p\left(M_{k}\right)=2^{-K}$ to all the models under consideration.

5. Given that the right-hand side of Fisher's equation is unknown, we assume that the value of the total transactions of goods and services is effectively proxied by the nominal GDP.

6. As shown by Ahumada et al. (2008), the estimate of $\left(\widehat{Y S}_{t}\right)$ will be biased if the circulation speeds in the official and hidden sectors differ. Thus, whenever $\widehat{\beta_{2}} \neq 1$, the outputs of applying Fisher's equation will be misleading.

7. The existing empirical evidence shows that $\widehat{\beta_{2}} \neq 1$. Mark and Soul (2003) report a value of 1.2, Hamori and Hamori (2008) a value of 4.13 and González-Fernández and González-Velasco (2015) a value oscillating between 1.15 and 1.34 .

8. The BMA estimates of $\hat{c}_{s t}$ are obtained as the probabilistic weighted average of all the specific $\hat{c}_{s t}$ predicted by each model $M_{k}$ such that $\hat{c}_{s t}=\exp \sum_{k=1}^{2^{K}}\left(\hat{C}_{s t} \mid M_{k}, C_{t}\right.$, Data $\left.t\right) p\left(M_{k} \mid C_{t}\right.$, Data $)$. Interestingly, our model-averaged estimate of the evolution of Currency Demand for hidden activities $\left(\widehat{c_{t}}\right)$ peaks in 2007 (at $€ 360$ million), which coincides with the peak of the housing bubble.

9. That is, we recompute a new weighted average of the shadow economy estimates implied by each tax indicator $j$ as $\widehat{S E}_{t}=\sum_{j} w_{j} \widehat{S E}_{t} \mid T_{j}$, where the weight is given by $w_{j}=\frac{\sum_{k} p\left(M_{j k}{ }^{\prime} \mid T_{j}\right)}{\sum_{j} \sum_{k} p\left(M_{j k}{ }^{\prime} \mid T_{j}\right)}$.

10. For comparison purposes, in Figure A2 of the Appendix we also provide the CDA estimates of the size of the shadow economy in Navarre that would be obtained when implementing a frequentist time series approach, rather than a BMA one. We find that our BMA implementation reduces the risk of overestimating shadow economy figures in Navarre. After averaging all the shadow economy time profiles derived from frequentist estimates during the 1986-2016 period, we note that the frequentist approach delivers an average size of $18.9 \%$ of the GDP, which is 3.6 points higher than that of the BMA approach.

11. To perform this comparison exercise, we use the same set of conditioning variables in $\mathrm{X}$ and $\mathrm{Z}$ within the BMA context.

12. Estimating the ratio of the shadow GDP to the official GDP in the KK1996 framework requires an initial assumption regarding $Y_{S, 0}$. This is taken from our previous estimate in the CDA-BMA for the base year 
1986, from which the calculations start. Specifically, we use $Y_{S, t}=Y_{T, t}-Y_{O, t}=10.25$, which generates a ratio $\frac{Y_{S, t}}{Y_{O, t}}=0.114$

13. The key parameter in the TVP estimation is the forgetting factor $\lambda$, which determines how rapidly the parameters of the model evolve. The intuition of $\lambda$ is that for the estimation of the parameters at time $t$, the observations that are $i$ periods old receive a weight $\lambda^{i}$ and the amount of data used for the estimate (or the window size) is $h=\frac{1}{(1-\lambda)}$. We experiment with values for $\lambda=0.99,0.95,0.9$ to verify the robustness. These are shown in Figure A1 in the Appendix.

14. The BMA econometric methodology employed here is identical to that used in the CDA-BMA, except for the inclusion of some specific determinants to explain electricity consumption and the fact that the ratio of the determinants that are considered fixed $H_{t, k}$ with respect to the number of variable factors $X_{t, q}$ is higher, leaving a smaller model space to explore with the $\mathrm{MC}^{3}$ sampler.

15. In this regard, we have estimated that on average, each $\mathrm{kWh}$ consumed produced $€ 4.24$. However, this level of energy productivity was not constant over time: it decreased by $10.2 \%$ from 1986 to 2003 and increased from 2004 to 2016. In the last year of our time sample, 2016, each kWh generated $€ 4.23$.

16. See Dell'Anno and Schenider (2009) for a detailed discussion of the benchmarking procedures used and Breusch (2005a, 2005b), Feige (2016a, 2016b) and Hashimzade and Heady (2016) for discussions and critiques of the MIMIC approach.

17. The identification problem in the MIMIC model arises because the structural model has $Q+1+\frac{Q(Q+1)}{2}$ parameters and the reduced form model has $Q P+\frac{P(P+1)}{2}+\frac{Q(Q+1)}{2}$ parameters.

18. We tried to include additional indicators such as the activity rate or the excess of electricity demand taken from the modified Lackó method, but when combined with GDP growth and currency growth, they generated numerical and convergence problems in the MIMIC estimation, which precluded us from increasing the number of cases.

19. The frequentist CDA estimate refers to the average of all shadow economy estimates obtained when considering the set of fiscal indicators $T_{t}$ described in Section 2.1 and when using $V_{2} V_{3}$ as our money velocity metric. The baseline regression employed to produce frequentist CDA results is given by:

$$
C_{t}=\alpha+\beta_{1} T_{t}+\beta_{2} \ln Y_{t}+\beta_{3} R_{t}+\beta_{4} \pi_{t}+\beta_{5} U_{t}+\beta_{6} \text { Euro }_{t}+\beta_{7} \text { Agri }_{t}+\beta_{8} \text { Cons }_{t}+\beta_{9} t+\beta_{10} t^{2}+\varepsilon_{t} \text {. }
$$

We were forced to exclude some $\mathrm{X}$ and $\mathrm{Z}$ factors discussed in CDA-BMA and the PIT-based shadow economy trajectory estimate due to numerical issues.

\section{References}

Ahumada, H., Alvaredo, F. and Canavese, A. (2007), “The Monetary Method and the Size of the Shadow Economy: A Critical Assessment", Review of Income and Wealth, 53(2): 363-371.

Ahumada, H., Alvaredo, F. and Canavese, A. (2008), “The Monetary Method to Measure the Shadow Economy: The Forgotten problem of the initial Conditions”, Economics Letters, 101(2): 97-99.

Alañón, A. and Gómez-Antonio, M. (2005), "Estimating the size of the shadow economy in Spain: a structural model with latent variables", Applied Economics, 37(9): 1011-1025.

Arrazola, M., Hevia, J., Mauleón, I. and Sánchez, R. (2011), "Estimación del volumen de economía sumergida en España”, Cuadernos de Información Económica, 220: 81-87. 
Ang, B. W., Wang, H.,and Ma, X. (2017), "Climatic influence on electricity consumption: The case of Singapore and Hong Kong”, Energy, 127: 534-543.

BBVA (2017), Situación Navarra 2017, Madrid: BBVA Research.

Bengtsson, E. and Waldenström, D. (2018), "Capital shares and income inequality: Evidence from the long run", The Journal of Economic History, 78(3): 712-743.

Blázquez-Gómez, L. M. B., Filippini, M. and Heimsch, F. (2013), "Regional impact of changes in disposable income on Spanish electricity demand: A spatial econometric analysis", Energy Economics, 40: S58-S66.

Bosco, B., Parisio, L., Pelagatti, M. and Baldi, F. (2010), "Long-run relations in European electricity prices", Journal of Applied Econometrics, 25(5): 805-832.

Breusch, T. (2005a), "The Canadian underground economy: An examination of Giles and Tedds", $\mathrm{Ca}$ nadian Tax Journal, 53: 367-391.

Breusch, T. (2005b), "Estimating the underground economy using MIMIC models", Working Paper, Camberra: The Australian National University.

Cagan, P. (1958), "The Demand for Currency relative to the Total Money Supply", Journal of Political Economy, 66(4): 303-328.

Camacho, C., Mariani, F. and Pensieroso, L. (2017), "Illegal immigration and the shadow economy", International tax and public finance, 24(6): 1050-1080.

Charron, N., Dijkstra, L. and Lapuente, V. (2014), "Regional governance matters: Quality of government within European Union member states", Regional studies, 48(1): 68-90.

Choi, S., Furceri, D., Huang, Y. and Loungani, P. (2018), “Aggregate uncertainty and sectoral productivity growth: The role of credit constraints", Journal of International Money and Finance, 88: 314-330.

Cover, J. P. and Hooks, D. L. (1993), "Money demand and income distribution: evidence from annual data", The Review of Economics and Statistics, 75(3): 520-523.

De la Fuente, A. (2017a), "Series enlazadas de algunos agregados económicos regionales, 1955-2014. Parte I: Metodología, VAB, PIB y puestos de trabajo, RegData 55-14, Versión 5.0-parte I", Documentos de trabajo FEDEA.

De la Fuente, A. (2017b), "Series enlazadas de algunos agregados económicos regionales, 1955-2014. Parte II: Otras variables de empleo, rentas del trabajo y paro, RegData 55-14, Versión 5.0-parte II", Documentos de trabajo FEDEA.

De la Fuente, A. (2017c), "Series largas de algunos agregados económicos y demográficos regionales: Actualización de RegData hasta 2016", Documentos de trabajo FEDEA.

Delgado, M. S., Henderson, D. J. and Parmeter, C. F. (2014), "Does education matter for economic growth?”, Oxford Bulletin of Economics and Statistics, 76(3): 334-359.

Dell'Anno, R. (2003), "Estimating the shadow economy in Italy: A structural equation approach", Working Paper 2003-7, Department of Economics, Aarhus, Denmark: University of Aarhus.

Dell'Anno R. (2007), “The Shadow Economy in Portugal: An Analysis with the MIMIC Approach”, Journal of Applied Economics, 10: 253-277.

Dell'Anno, R., Gómez-Antonio, M. and Pardo, A. (2007), “The shadow economy in three Mediterranean countries: France, Spain and Greece. A MIMIC approach", Empirical Economics, 33(1): 51-84. 
Dell'Anno, R. and Schneider, F. (2009), "A Complex Approach to Estimate Shadow Economy: The Structural Equation Modelling", 111-130, M. Faggini and T. Lux, eds. (2009), Coping with the Complexity of Economics, Springer, Milan.

Dybka, P., Kowalczuk, M., Olesiński, B., Torój, A. and Rozkrut, M. (2019), “Currency demand and MIMIC models: towards a structured hybrid method of measuring the shadow economy", International Tax and Public Finance, 26(1): 4-40.

Esteller, A. (2021), "Imposición óptima y descentralización fiscal: el caso del IRPF”, Investigaciones Regionales - Journal of Regional Research, 49: 29-44.

Feige, E. L. (2016a), "Reflections on the Meaning and Measurement of Unobserved Economist: What Do We Really Know About the Shadow Economy?", Journal of Tax Administration, 2/2: 5-41.

Feige, E. L. (2016b), "Professor Schneider's Shadow Economy (SSE): What Do We Really Know? A Rejoinder", Journal of Tax Administration, 2/2: 93-107.

Feldstein, M. S. (1996), “The Costs and Benefits of Going from Low Inflation to Price Stability”, NBER Working Paper, 5469.

Fernández-Leiceaga, X., Lago-Peñas, S., Martínez-Vázquez, J. and Vaquero-García, A. (2018), Economía Sumergida y Fraude Fiscal en España. ¿Qué Sabemos? Una Panorámica de la Literatura, Chapter 1: 17-47, Madrid: Funcas.

Frey, B. S. and Weck, H. (1983), "Estimating the shadow economy: a naïve approach", Oxford Economic Papers, 35: 23-44.

Frey, B. S. and Weck-Hanneman, H. (1984), “The hidden economy as an unobserved variable”, European Economic Review, 2(1-2): 33-53.

Gadea, M. D. and Serrano-Sanz, J. M. (2002), "The hidden economy in Spain - A monetary estimation, 1964-1998”, Empirical Economics, 27: 499-527.

Giles, D. E. A. (1999a), "Measuring the Hidden Economy: Implications for Econometric Modelling", Economic Journal, 109(3): 370-380.

Giles, D. E. A. (1999b), "Modeling the hidden economy in the tax-gap in New Zealand", Empirical Economics, 24: 621-640.

Giles, D. E. A. and Tedds, L. M. (2002), "Taxes and the Canadian underground economy", Canadian Tax Paper, vol. 106. Toronto: Canadian Tax Foundation.

Gill, C. and Lang, C. (2018), "Learn to conserve: The effects of in-school energy education on at-home electricity consumption”, Energy Policy, 118: 88-96.

Goel, R. K. and Nelson, M. A. (2016), "Shining a light on the shadows: Identifying robust determinants of the shadow economy", Economic Modelling, 58: 351-364.

González-Fernández, M. and González-Velasco, C. (2015), "Analysis of the shadow economy in the Spanish regions", Journal of Policy Modeling, 37(6): 1049-1064.

Gutmann, P. M. (1977), “The subterranean economy”, Financial Analysts Journal, 33(6): 26-34.

Hamilton, J. D. (2009), “Understanding crude oil prices”, The Energy Journal, 30(2): 179-206.

Hamori, S. and Hamori, N. (2008), "Demand for money in the Euro area", Economic Systems, 32: 274-284. 
Hashimzade, N. and Heady, C. (2016), "Reflections on the Meaning and Measurement of Unobserved Economies: An Editorial Comment”, Journal of Tax Administration, 2/2: 108.

Hassan, M. and Schneider, F. (2016a), "Modelling Egyptian Shadow Economy: A MIMIC Model and the Currency Demand Approach", Journal of Economics and Political Economy, 3(3): 309-339.

Hassan, M. and Schneider, F. (2016b), "Size and Development of Shadow Economies of 157 World Wide Countries, Updated New Measures from 1999-2013”, Journal of Global Economics, 4(3): 1-14.

Hausmann, R., Hidalgo, C. A., Bustos, S., Coscia, M. and Simoes, A. (2014), The atlas of economic complexity: Mapping paths to prosperity, Cambridge, Mass.: MIT Press.

Helberger, C. and Knepel, H. (1988), "How Big is the Shadow Economy? A Re-Analysis of the Unobserved Variable Approach of B.S. Frey and H. Weck-Hannemann", European Economic Review, 32: 965-976.

Hor, C. L., Watson, S. J. and Majithia, S. (2005), "Analyzing the impact of weather variables on monthly electricity demand", IEEE transactions on power systems, 20(4): 2078-2085.

Horodnic, I. A. (2016), "Cash wage payments in transition economies: consequences of envelope wages", IZA World of Labor, 280.

Johnson, S., Kaufmann, D. and Shleifer, A. (1997), “The unofficial economy in transition”, Brookings Papers on Economic Activity, 2: 159-239.

Johnson, S., Kaufmann, D. and Zoido-Lobatón, P. (1998), "Corruption, public finances and the unofficial economy", Policy Research Working Paper 2169, Washington DC: The World Bank.

Jones, D. W., Leiby, P. N. and Paik, I. K. (2004), "Oil price shocks and the macroeconomy: what has been learned since 1996", The Energy Journal, 25(2): 1-32.

Kaufmann, D. and Kaliberda, A. (1996), "Integrating the unofficial economy into the dynamics of post socialist economies: a framework of analyses and evidence", Policy Research Working Paper 1691, Washington DC: The World Bank.

Koulayev, S., Rysman, M., Schuh, S. and Stavins, J. (2016), "Explaining adoption and use of payment instruments by US consumers", The RAND Journal of Economics, 47(2): 293-325.

Lackó, M. (1996), "Hidden economy in East-European countries in international comparison”, Working paper, Luxemburg: International Institute for Applied Systems Analysis (IIASA).

Lackó, M. (1998), "The Hidden Economies of Visegrad Countries in International Comparison: A Household Electricity Approach", in: Halpern, L. and Ch. Wyplosz (eds.), Hungary: Towards a Market Economy, Cambridge, Mass.: Cambridge University Press.

Lackó, M. (2000), "Hidden Economy-an Unknown Quantity? Comparative Analysis of Hidden Economies in Transition Economies, 1989-95", Economics of Transition, 8(1): 117-149.

Lee, C. C. and Chiu, Y. B. (2011), "Electricity demand elasticities and temperature: Evidence from panel smooth transition regression with instrumental variable approach", Energy Economics, 33(5): 896-902.

Loayza, N. V. (1996), "The economics of the informal Sector: a simple model and some empirical evidence from Latin America", Carnegie-Rochester Conference Series on Public Policy, 45: 129-162.

Macias, J. B. and Cazzavillan, G. (2010), "Modeling the informal economy in Mexico: a structural equation approach", Journal of Developing Areas, 44(1): 345-365. 
Mark, N. C. and Soul, D. (2003), "Cointegration vector estimation by panel DOLS and long-run money demand", Oxford Bulletin of Economic and Statistics, 65: 665-680.

Mohammadi, H. (2009), "Electricity prices and fuel costs: Long-run relations and short-run dynamics", Energy Economics, 31(3): 503-509.

Moral-Benito, E. (2015), "Model averaging in economics: An overview", Journal of Economic Surveys, 29(1): 46-75.

Muñoz Delgado, B. and Rubio-Varas, M. (2017), "Energy planning, nuclear promises, and realities”, in Rubio-Varas and De la Torre (eds.), The Economic History of Nuclear Energy in Spain: Governance, Business and Finance, 217-248, London: Palgrave.

Novkovska, B. and Novkovski, N. (2018), "Energy consumption and hidden economy in Macedonia: Causes and responses", Journal of Policy Modeling, 40(1): 166-181.

OECD (2002), Measuring the Non-Observed Economy: A Handbook, Paris: OECD Publishing.

OECD (2017), Shining Light on the Shadow Economy: Opportunities and Threats, Paris: OECD Publishing.

Pérez García, F. (dir.), Cucarella Tormo, V., Fernández García, A. and Hernández Lahiguera, A. (2011), Las diferencias regionales del sector público español, Madrid: Fundación BBVA.

Pickhardt, M. and Sardà, J. (2015), "Size and causes of the underground economy in Spain: a correction of the record and new evidence from the MCDR approach", European Journal of Law and Economics, 39(2): 403-429.

Prado-Domínguez, A. J. (2004), “Una estimación de la economía informal en España según un enfoque monetario, 1964-2001”, El Trimestre Económico, 71(82): 417-452.

Raftery, A. E., Karny, M. and Ettler, P. (2010): “Online prediction under model uncertainty via dynamic model averaging: application to a cold rolling mill", Technometrics, 52: 52-66.

Rua, A. (2018), "Modelling currency demand in a small open economy within a monetary union", Economic Modelling, 74: 88-96.

Schneider, F. (2005), "Shadow economies around the world: What do we really know?", European Journal of Political Economy, 21(3): 598-642.

Schneider, F. (2007), "Shadow Economies and Corruption All Over the World: New Estimates for 145 Countries", The Open-Access, Open-Assessment E-Journal, 1 (2007-9): 1-53 (Version 2).

Schneider, F. (2010), "Size and development of the shadow economy of 31 European countries from 2003 to 2010", Working Paper, University of Linz. Available at http://www.econ.jku.at/members/Sch neider/files/publications/LatestResearch2010/ShadEcEurope31_October2010_RevisedVersion.pdf.

Schneider, F. (ed.) (2011), Handbook on the Shadow Economy, Cheltenham: Edward Elgar.

Schneider, F. (2013), “The shadow economy in Europe", 2013. Available at: https://www.atkearney. com/documents/10192/1743816/The+Shadow+Economy+in+Europe+2013.pdf.

Schneider, F. (2016), "Comment on Feige's Paper, Reflections on the Meaning and Measurement of Unobserved Economies: What Do We Really Know About the Shadow Economy?", Journal of Tax Administration, 2(2): 82-92.

Schneider, F. and Buehn, A. (2017), "Estimating a Shadow Economy: Results, Methods, Problems, and Open Questions", Open Economics, 1: 1-29. 
Schneider, F., Buehn, A. and Montenegro, C. E. (2010), "Shadow economies all over the world. New Estimates for 162 countries from 1999-2007”, Policy Research Working Paper, Washington DC: The World Bank.

Schneider, F. and Enste, D. H. (2000), "Shadow Economies: Size, Causes, and Consequences", Journal of Economic Literature, 38(1): 77-114.

Schneider, F. and Enste, D. H. (2013), The Shadow Economy. An International Survey, 2nd Edition, Cambridge: Cambridge University Press.

Schneider, F. and Williams, C. C. (2013), The Shadow Economy, London: Institute of Economic Affairs.

Schwab, K. (2018), The global competitiveness report 2018, Geneva: World Economic Forum.

Shahbaz, M., Sarwar, S., Chen, W. and Malik, M. N. (2017), "Dynamics of electricity consumption, oil price and economic growth: Global perspective", Energy Policy, 108: 256-270.

Sorens, J. (2014), "Does Fiscal Federalism Promote Regional Inequality? An Empirical Analysis of the OECD, 1980-2005”, Regional Studies, 48(2): 239-253.

Steel, M. F. (2020), "Model averaging and its use in economics", Journal of Economic Literature, 58(3): 644-719.

Stern, D. I. (2019), "Energy and economic growth", in, Soytas, U. and Sari, R. (eds.), Handbook of Energy Economics, 28-46, London: Routledge.

Tafenau, E., Herwartz, H. and Schneider, F. (2010), "Regional estimates of the shadow economy in Europe", International Economic Journal, 24(4): 629-636.

Tanzi, V. (1983), “The Underground Economy in the United States: Annual Estimates, 1930-80”, IMF Staff Papers, 30(2): 799-811.

Tanzi, V. (1999), "Uses and abuses of estimates of the underground economy", The Economic Journal, 109(456): 338-347.

Tedds, L. M. (2005), "The Underground Economy in Canada", in, Bajada, C. and Schenider, F. (eds.), Size Causes and Consequences of the Underground Economy, Ashgate, UK: Aldershot.

Thieben, U. (2010), “The Shadow Economy in International Comparison: Options for Economic Policy Derived from an OECD Panel Analysis”, International Economic Journal, 24(4): 481-50

Zeugner, S. and Feldkircher, M. (2015), "Bayesian model averaging employing fixed and flexible priors: The BMS package for R", Journal of Statistical Software, 68(4): 1-37.

Zubiri, I. (2015), "Un análisis del sistema foral de la Comunidad Autónoma del País Vasco y sus ventajas durante la crisis", Papeles de Economía Española, 143: 205-224.

Zubiri, I., Fernández-Macho, J. and Gallastegui, M. C. (2016): Economía sumergida y fraude fiscal en la C. A. de Euskadi. Available at: https://bit.ly/3hf6BUW.

\section{Resumen}

En este artículo se estima el tamaño de la economía sumergida en una región española (Navarra) para el período 1986-2016. Se han empleado métodos macroeconométricos indirectos, como el enfoque de Demanda de efectivo, dos métodos de Consumo de electricidad (inputs físicos) y el enfoque de Múltiples Indicadores y Múltiples Causas (MIMIC). Una característica diferencial del análisis empírico es 
la incorporación de varias innovaciones metodológicas (por ejemplo, el promediado bayesiano de modelos, un modelo de parámetros que varían en el tiempo, o la normalización de la variable latente) para refinar y aumentar la precisión de medición de cada uno de los métodos indirectos considerados. El patrón temporal del tamaño de la economía sumergida que surge de los diferentes enfoques es similar, lo que sugiere que las estimaciones obtenidas son sólidas y capturan la dinámica subyacente del sector oculto. Después de cuantificar la economía sumergida, se analizan sus determinantes mediante técnicas de promediado bayesiano de modelos. Encontramos que la evolución de la economía sumergida en Navarra puede explicarse por un conjunto pequeño y robusto de factores: la carga fiscal, el empleo en el sector de la construcción, la tasa de inflación, la pertenencia a la zona euro y la ratio del efectivo fuera de los bancos en relación a M1.

Palabras clave: economía sumergida, demanda de efectivo, consumo de electricidad, MIMIC, promediado bayesiano de modelos.

Clasificación JEL: E26, H26, O17. 